\title{
Chronobiology Revisited in Psychiatric Disorders: From a Translational Perspective
}

\author{
Simge Seren Kirlioglu and Yasin Hasan Balcioglu $\bowtie$ \\ Department of Psychiatry, Bakirkoy Prof Mazhar Osman Training and Research Hospital for Psychiatry, Neurology and Neurosurgery, \\ Istanbul, Turkey
}

Objective Several lines of evidence support a relationship between circadian rhythms disruption in the onset, course, and maintenance of mental disorders. Despite the study of circadian phenotypes promising a decent understanding of the pathophysiologic or etiologic mechanisms of psychiatric entities, several questions still need to be addressed. In this review, we aimed to synthesize the literature investigating chronobiologic theories and their associations with psychiatric entities.

Methods The Medline, Embase, PsycInfo, and Scopus databases were comprehensively and systematically searched and articles published between January 1990 and October 2019 were reviewed. Different combinations of the relevant keywords were polled. We first introduced molecular elements and mechanisms of the circadian system to promote a better understanding of the chronobiologic implications of mental disorders. Then, we comprehensively and systematically reviewed circadian system studies in mood disorders, schizophrenia, and anxiety disorders.

Results Although subject characteristics and study designs vary across studies, current research has demonstrated that circadian pathologies, including genetic and neurohumoral alterations, represent the neural substrates of the pathophysiology of many psychiatric disorders. Impaired HPA-axis function-related glucocorticoid rhythm and disrupted melatonin homeostasis have been prominently demonstrated in schizophrenia and other psychotic disorders, while alterations of molecular expressions of circadian rhythm genes including CLOCK, PER, and CRY have been reported to be involved in the pathogenesis of mood disorders.

Conclusion Further translational work is needed to identify the causal relationship between circadian physiology abnormalities and mental disorders and related psychopathology, and to develop sound pharmacologic interventions.

Psychiatry Investig 2020;17(8):725-743

Key Words Biological clocks, Circadian rhythm disorders, Mental disorders, Melatonin, HPA-axis.

"There is a time for many words, and there is also a time for sleep." Homer, 850 BC

\section{INTRODUCTION}

Rhythmicity is a fundamental characteristic of the nature of life. Time as a dynamic and complex phenomenon, plays a pivotal role to sustain rhythmicity for the biologic essentials and needs of living organisms. Chronobiology aims to define basic

Received: April 7, 2020 Revised: May 14, 2020 Accepted: May 15, 2020

$\triangle$ Correspondence: Yasin Hasan Balcioglu, MD, PhD Department of Psychiatry, Bakirkoy Prof Mazhar Osman Training and Research Hospital for Psychiatry, Neurology and Neurosurgery, Istanbul 34147, Turkey

Tel: +0090 212409 1515, E-mail: yhasanbalcioglu@gmail.com

(a) This is an Open Access article distributed under the terms of the Creative Commons Attribution Non-Commercial License (https://creativecommons.org/licenses/by$\mathrm{nc} / 4.0$ ) which permits unrestricted non-commercial use, distribution, and reproduction in any medium, provided the original work is properly cited. principles of vital reactions that occur nearly 24 hours per day through circadian rhythms and biologic processes in anything from single cells to human beings. The first scientific awareness of circadian rhythms started with observations of the mimosa plant (Mimosa pudica) folding independent of daylight by the French astronomer Jean Jacques d'Ortous de Mairan, in $1729 .{ }^{1}$ In the 1930s, the German biologist Erwin Bünning subsequently noticed that the movement of the bean plant had an intrinsic period that did not change under constant light conditions and inferred that such periodic alterations were arranged with an endogenous clock. ${ }^{1}$

The term 'circadian' was first used by Franz Halberg in 1959. It means 'about a day' and an endogenous day slightly shorter or longer than 24 hours (from the Latin term circa: about and diem: day) depending on constant conditions, preserved from environmental factors. ${ }^{2}$ Uncovering interactions between molecules and cells within an endogenous day was a major advance- 
ment in the discovery of the essential mechanism of circadian rhythm, which was a remarkable scientific milestone in chronobiology. It had been eagerly attempted to explain the further molecular mechanisms of circadian rhythm; however, the oscillation process could not be unraveled until 1971. Konopka and Benzer ${ }^{3}$ first determined a gene by observing the differences of circadian period lengths among three mutant flies. They demonstrated three mutants, one was arrhythmic, another had a shorter period of $19 \mathrm{~h}$, and the third had a longer period of $28 \mathrm{~h}$; flies with neither the short-period gene nor the long-period gene or the arrhythmic gene would not produce a normal rhythm. They concluded that the same functional gene with a point mutation appeared to be affected in all cases. This work inspired Jeffery C. Hall, Michael Rosbash, and Michael Young, independently. They cloned and rescued the Drosophila Period gene, which was recognized as the first clock gene, found in 1984. ${ }^{4,5}$ They defined the transcriptional translational feedback loop (TTFL) model with the analysis of Per gene expression and they demonstrated additional genes and proteins in further work. The simple genetic model they postulated revealed the generation of an autonomous oscillator, including transcription-translation cycles from interacting positive and negative feedback loops that depend on ribonucleic acid (RNA) and protein levels, which is still used to understand circadian rhythms. Consequently, they were awarded the Nobel Prize in Physiology and Medicine in 2017 for their explanatory findings of molecular mechanisms controlling the circadian rhythm. ${ }^{6}$

Despite the fact that the understanding of the neural basis of rhythmicity and central nervous system (CNS) involvement in circadian mechanisms is not long-standing knowledge, the discovery of the suprachiasmatic nucleus (SCN) of the anterior hypothalamus, which was later described as the master circadian pacemaker in mammals, is actually not very recent. The SCN was first defined as a cluster of different neurons in the 1880 s and was subsequently recognized in a number of mammalian species' brains through comparative studies of the hypothalamus by Crosby and Woodburne., ${ }^{7,8}$ However, the discovery of its regulatory function on circadian rhythm occurred nearly 100 years later. The SCN contains a complex neurochemical organization and its functional organization had been revealed with comprehensive experimental studies regarding the function of localization, the neuronal mini-network it contains, and its role in the circadian system. Consequently, the SCN is recognized as a coordinator of biologic processes regulating numerous cellular clocks of the brain and other organ systems.

The findings of considerable studies revealing that a broad range of cell types in the body and brain have biologic clocks raised questions regarding the specific function of circadian rhythm and its contribution to illnesses. Circadian rhyhthms in peripheral organ systems and their impeccable relationship with the SCN and other physiologic and metabolic mechanisms are essential for physical and mental health. The internal desynchronization between the central and peripheral clocks which may be a result of shiftwork or diversity of clock genotypes or circadian rhythm sleep disorders including delayed sleep phase disorder, advanced sleep phase disorder, non-entrained type, irregular sleep-wake rhythm, shift work sleep disorder and jet lag disorder have been associated with many illnesses including metabolic dysfunctions, obesity, cancer, and mental disorders. $^{9,10}$

Circadian rhyhtms disruption refers to a range nosological penumbra that includes changes in phase and amplitude of circadian rhythms, circadian misalignment, altered phase relationship between the sleep-wake cycles and endogenous circadian rhythms. Therefore, we would like to provide brief information about descriptions of circadian rhyhtms disruption types. The amplitude of a function is the distance between the mean value and the peak. Therefore, the amplitude resembles half the range of oscillation. Amplitude of the circadian rhythm is involved in the sleep-wake cycle and the changes in amplitude lead to the changes of timing and consolidation of sleep and wakefulness. ${ }^{11}$ Phase is also one of the parameters that characterize a circadian rhythm. The circadian pacemaker is known to drive a number of physiologic variables including body temperature and the rhythms of melatonin and cortisol through suprachiasmatic nuclei. ${ }^{12}$ The phase of the circadian rhythms is mostly determined by both genetic and environmental factors such as routine daily activities and sunlight. The internal phase advance of biological rhythms which reflects any disturbance of either sleep-wake cycle or endogenous circadian rhythms is related to illnesses and aging. ${ }^{11}$ The term "circadian misalignment" describes a range of circumstances, such as inappropriately timed sleep and wake, misalignment of sleep/ wake with feeding rhythms, or misaligned central and peripheral clocks. ${ }^{13}$ Another subtype of circadian misalignment includes the misalignment of body rhythms with environmental cycles that is usually found in night-shift workers characterizes a condition of chronic desynchronization similar to that produced by persistent jet lag. Different types of circadian misalignment have been associated with increased risk for both physical and psychiatric disorders. ${ }^{13}$

Circadian rhythms abnormality, a common manifestation of nearly all psychiatric disorders, is not a surprising predisposing factor for mental disorders, because sleep is considered as a cardinal psychological and vital function and requires routine evaluation in every mental state examination. The common disrupted mechanisms related to the circadian rhythm in psychiatric disorders could be determined as the melatonergic system, its effects of sleep pattern, and the hypothalamus-pituitary-adrenal (HPA) axis. Besides, studies of human circadian 
rhythm genes revealed that genetic polymorphisms of these genes predisposed to psychiatric disorders. ${ }^{14-16}$ Therefore, circadian disturbances seem to be the common thread to all these possible underlying mechanisms that contribute to illness onset, maintenance, and even the response to treatment. Special attention ought to be paid toward the physiology and pathology of circadian rhythm to understand the etiology of psychiatric disorders, and to develop appropriate treatment strategies because chronobiology is an essential field of work in mental disorders. Related literature provides information on circadian rhythm disturbances for certain psychiatric diagnoses such as schizophrenia, mood and anxiety disorders. However, we are aware of a lack of a comprehensive perspective of molecular and neural substrates of common disrupted circadian mechanisms to clinical manifestations in psychiatric disorders. There have been recent reviews relevant to the subject. For instance, Jones and Benca ${ }^{17}$ reviewed circadian disruptions in psychiatric disorders, however, they only focused on schizophrenia and mood disorders. Wulff et al. ${ }^{18}$ and colleagues comprehensively reviewed sleep and circadian rhythms disruption in psychiatric disorders. Nevertheless, their review was lack of findings regarding current genetic, molecular and neurohumoral models of circadian pathologies. Therefore, we aimed to present a comprehensive review from a translational perspective regarding the reciprocal relationship between neurobiologic underpinnings of circadian rhythm pathologies and psychiatric disorders in this article.

\section{Searching strategy and selection criteria of reviewed studies}

An electronic database search was performed by the authors in the MEDLINE, Embase, PsycInfo, and Scopus databases for relevant articles published between January 1990 and October 2019. We searched reference lists of relevant reviews. Different combinations of the keywords psychiatric disorder, mental disorder, mood disorder, bipolar disorder, depression, unipolar depression, major depressive disorder, schizophrenia, psychotic disorders, anxiety disorders, circadian rhythms, circadian markers, chronotype, chronobiology, circadian gene, clock gene, melatonin, and HPA axis were polled. Articles published only in English were reviewed. Unpublished studies, case reports, theses, and conference papers were excluded. Several highly cited and regarded comprehensive review articles and meta-analyses are cited due to space considerations. Eligible open-access and institutional-access articles were recruited. The articles were filtered through an inspection of the abstracts in order to select the most suitable articles related to the topic. In addition to database searches, the reference lists of the relevant articles were also evaluated manually for additional publications matching the scope of our review. The authors avoided incorporating duplicated samples of the key papers; however, studies with similar methodology were included if they provide essential findings to the literature. The visulised algorithm of the article selection is shown in Figure 1.

\section{MOLECULAR REGULATION OF THE CIRCADIAN RHYTHM}

We believe that it is noteworthy to briefly summarize the molecular underpinnings of circadian science that gave input to the research into neural substrates of rhythmicity. Although the aforementioned discovery of the period gene was a remarkable finding that identified a genetic determination of the biological clock, it did not mean comprehension of all circadian molecular mechanisms. The circadian rhythm started to be more understandable with the determination of alterations in PER protein and period mRNA levels during a day. Hardin et al..$^{19}$ ascertained that levels of period mRNA peaked in the early night, several hours earlier than the peak PER protein abundance. The TTFL model emerged with the discovery of further circadian rhythm genes found in subsequent studies. According to this model, PER and TIM (a protein encoded by the timeless gene) proteins transformed into a heterodimer form in the cytoplasm in order to translocate into the nucleus. TIM protein allows nuclear entry of PER. ${ }^{20}$ Besides CLOCK and CYCLE \{orthologues of mammalian CLOCK and BMAL-1 [a protein encoded by the brain muscle ARNT-like protein-1 (Bmal-1) gene], respectively\} constitute a protein couple that supports the transcription of period and timeless genes [the equivalent of period 1-3 and cryptochrome 1-2 (Cry) in mammalian cells] in the nucleus. ${ }^{21,22}$ When the PER-TIM heterodimer binds to the CLOCKCYCLE couple, CLOCK-CYCLE segregates from DNA and the transcription of downstream genes related to PER and TIM conclude. In other words, the PER and TIM heterodimer terminate their transcription. However, in the event of a decrement in PER and TIM protein levels, the CLOCK and CYCLE couple activates their transcription once again, and TTFL starts over. All of these biochemical reactions include transcription and translation processes that occur rapidly. However, a near 24-h period needs a delay period and timeless gene transcriptions. The explanation about the regulation of the needed delay comes from the discovery of the doubletime gene, another member of the clock genes. ${ }^{23,24}$ The doubletime gene's product casein kinase-1 (CSNK-I $\varepsilon$; casein kinase 1 epsilon in mammals) phosphorylates PER for degradation. Thus, activity of the doubletime gene reduces the stability and accumulation of PER, thereby promoting a delay between PER-TIM transcription and PER-TIM nuclear function. ${ }^{6,25}$ This molecular mechanism occurs both in the SCN and nearly all peripheral cells.

The maestro of chronophysiologic rhythms including body 


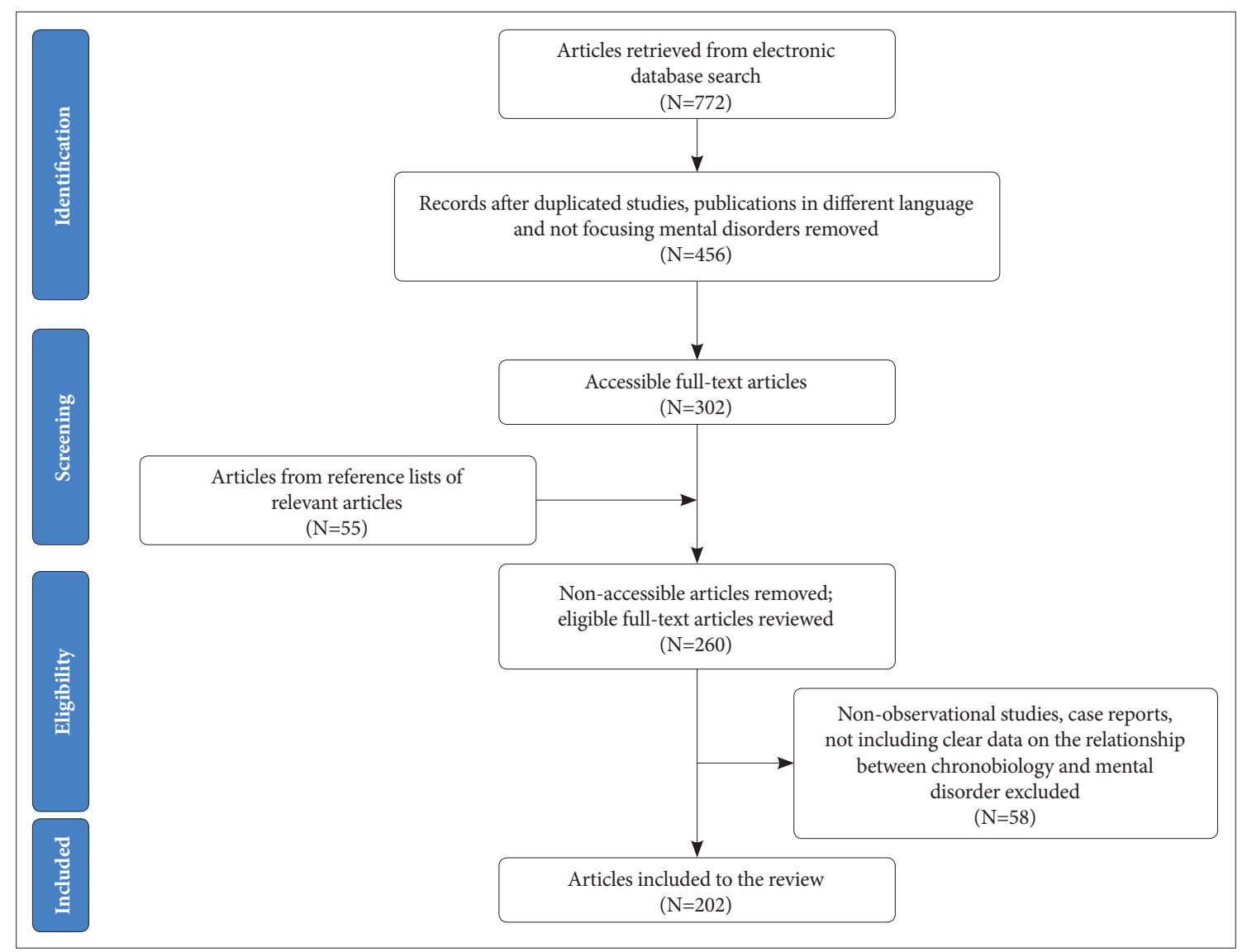

Figure 1. Flowchart of articles selected for the review.

temperature, sleep-wake cycle motor activity, and neuroendocrine functions, is located in the SCN of the hypothalamus. The clock genes in the peripheral cells such as hepatocytes, adipocytes or epidermal and dermal cells have their own rhythmicity; however, cyclic processes in which the SCN is involved provide an integrative organization of the physiologic functions and behavioral outputs of the body. ${ }^{26,27}$ The circadian system sustains an endogenous rhythmic activity in spite of environmental cues. Regardless of the presence of light, the neuronal activity in the SCN occurs at a higher frequency during the day compared with the night. The neurons of the SCN tend to be excitable in the day to maintain spontaneous activity through persistent $\mathrm{Na}^{++}$currents, oscillations in chloride pumps, $\mathrm{K}^{+}$channels, and $\mathrm{Ca}^{++}$pools in the morning. Conversely, hyperpolarized neurons are inhibited and keep the silence in the SCN at night. ${ }^{28}$ CRY and PER proteins gather in the cytoplasm before translocating into the nucleus where they inhibit CLOCK-BMAL-1 activity during the night. In other words, CRY and PER proteins terminate their own transcription when they inhibit CLOCKBMAL-1 complex activity. After that, degradation of PER and CRY manages the inhibition of CLOCK-BMAL1 toward the morning, followed by resumed transcription of period/cryptochrome and other clock genes. ${ }^{29}$

\section{Involvement of master clock in the regulation of circadian rhythm}

The master clock synchronizes the endogenous rhythm to the external world, mainly in the presence of major environmental input-light. ${ }^{30-32}$ A specialized tract, called the retino-hypothalamic tract, which starts from the retinal ganglion cells that include the essential photoreceptor pigment melanopsin, and terminating at the SCN. This tract aids upregulation of clock gene expression and increases neuronal activity in the SCN. ${ }^{33,34}$ Nevertheless, functions of the SCN, such as synchronization by the light/dark cycle, do not only depend on this molecular mechanism. Many inputs of the SCN have been determined including melatonin, food intake, blood pressure, and physical activity. ${ }^{35-38}$ In addition, the SCN receives non-photic timing inputs from the raphe nucleus, which means the serotoninergic system plays a substantial role in the regulation of circadian rhythm..$^{39}$ Furthermore, the SCN serves in the excretion of numerous neurotransmitters that interact with other hypothalamic structures, hence neuropeptidergic signaling maintains circadian rhythm of the SCN. Consequently, the biologic interactions between the brain and body are modulated by the $\mathrm{SCN}$, which is critically involved in the organism's adjustment to the environment through the impact of internal signals, which 
are mediated by hormonal rhythms, the autonomic nervous system, and external time indicators such as light and food intake. ${ }^{10}$ The master clock regulates the endogenous rhythm in response to environmental inputs and dysfunction of the master clock could contribute to a wide range of illnesses including obesity, diabetes mellitus, autoimmune disorders, and particularly mental disorders. ${ }^{40-44}$ Disruption that arises due to a misalignment between inner physiology and the external world or a clock gene polymorphism may facilitate the emergence of diseases, increased disease severity and worsened prognosis, and heightened risk for poor treatment outcomes. ${ }^{45,46}$ Clock genes, their main functions and association with psychiatric disorders summarized in Table 1.

\section{NEUROHUMORAL AND HORMONAL REGULATION OF CIRCADIAN RHYTHM}

The SCN collects information about the endogenous clocks through nervous projections and peripheral hormones. The SCN's monosynaptic outputs mainly target the pre-autonomic neurons of the paraventricular nucleus (PVN) in the hypothalamus. The $\mathrm{SCN}$ is directly involved in the hypothalamic output to the preganglionic parasympathetic regions of the brainstem and to sympathetic preganglionic motor neurons of the spinal cord. ${ }^{94-96}$ These projections allow the $\mathrm{SCN}$ to command the rhythmic control of hormone release and metabolism of all visceral structures through parasympathetic and sympathetic outputs. It has been determined that the SCN could increase glucose production from the liver through the sympathetic output to the liver with its projections that reach to the PVN ${ }^{97} \mathrm{Sim}-$ ilarly, the SCN could increase corticosterone secretion in the adrenal or support glucose uptake into the muscle cells via sympathetic activation. ${ }^{98-100}$ Besides, hormonal signals predominantly controlled by the SCN have a critical role in the regulation of internal synchronization. ${ }^{27}$ Internal synchronization is supplied by adrenal glucocorticoids, pineal melatonin, adipocyte-derived leptin, pancreatic insulin or stomach ghrelin induced by the SCN. Internal synchronization included many multi-synaptic neuronal pathways that modulate behavior. For example, leptin increases during food intake in rats, ghrelin increases following a fasting period, and adrenaline increases with locomotor activity. ${ }^{100-102}$

Glucocorticoids are produced in the adrenal glands from cholesterol and rhythmically released at ultradian (pulsatile) and circadian (daily) scales. Glucocorticoid release peaks typically prior to the onset of physical activity and depends on the fluctuations of corticotropin (adrenocorticotropic hormone, ACTH), a polypeptide secreted from the anterior pituitary under the control of corticotropin-releasing hormone (CRH), during the day. Glucocorticoid levels are regulated by a complex interac- tion between the adrenal clock and sympathetic outputs from the PVN and SCN. ${ }^{103}$ Furthermore, the daily variation of glucocorticoids is influenced by stressful life events that activate the HPA axis and the autonomous nervous system. Glucocorticoid rhythm has a crucial role in the regulation of other hormonal rhythms and peripheral oscillations of metabolic gene expressions in the cells of tissues such as liver and white adipose tissue. ${ }^{103}$

On the other hand, adrenal glucocorticoids can modulate the synchronization of the master clock to light via serotonergic projections from the raphe nucleus. ${ }^{104}$ Serotonergic neurons release serotonin in the presence of glucocorticoid and locomotor activity. Such neuronal activity ensures transmitting feedback to the SCN in order to sustain the functioning of the clock itself. ${ }^{105}$ In other words, serotonergic projections stimulated by locomotor activity provide a re-synchronization of the SCN. ${ }^{106}$ Furthermore, brain serotonin synthesis and catabolism have their own circadian rhythm, closely related to the SCN. Neuronal serotonin release in the $\mathrm{SCN}$ is provided in the absence of photic stimulation, and serotonin levels increase in the raphe nucleus after the beginning of the dark phase. ${ }^{107}$ Tryptophan hydroxylase $(\mathrm{TpH})$, the rate-limiting enzyme in the synthesis of serotonin, is one of the regulators of circadian rhythm in the raphe nucleus. It is known that $\mathrm{TpH}$ peaks during the dark phase, helping the interaction between the serotoninergic system and the SCN through the increment of serotonin levels. ${ }^{107}$ Also, serotonergic neurotransmission alterations could cause phase shifts and changes in SCN activity affecting the phosphorylation of CLOCK proteins. ${ }^{108}$

Melatonin, a member of the class of acetamides, is another hormone related to biologic rhythm. It is primarily released by the pineal gland, particularly at night. Melatonin release is adjusted by the length of night time and melatonin per se regulates the seasonality of energy metabolism and reproduction in photoperiodic species. ${ }^{109}$ Melatonin secretion peaks a few hours before sleep or at the time of minimal vigilance propensity, and decreases as wakefulness approaches under normal conditions. ${ }^{110}$ In contrast, core body temperature reaches the highest degree during the day and has a nocturnal decline related to the melatonin peak. ${ }^{111}$ This inverse relationship between melatonin and core body temperature is organized by the SCN. The nocturnal release of melatonin is induced by the $\mathrm{SCN}$ input to the PVN noradrenergic (sympathetic) afferents to the pineal gland. ${ }^{100}$ Melatonin accumulates sleep both by setting the SCN and inhibiting neural centers such as the locus coeruleus (LC) and raphe nuclei, which mediate arousal through the ventrolateral preoptic nucleus of the hypothalamus (VLPO). It has been determined that melatonin receptor agonists increase monoaminergic neuronal activity and contribute to the regulation of dopamine and 5-HT neurotransmission. ${ }^{112}$ In other 


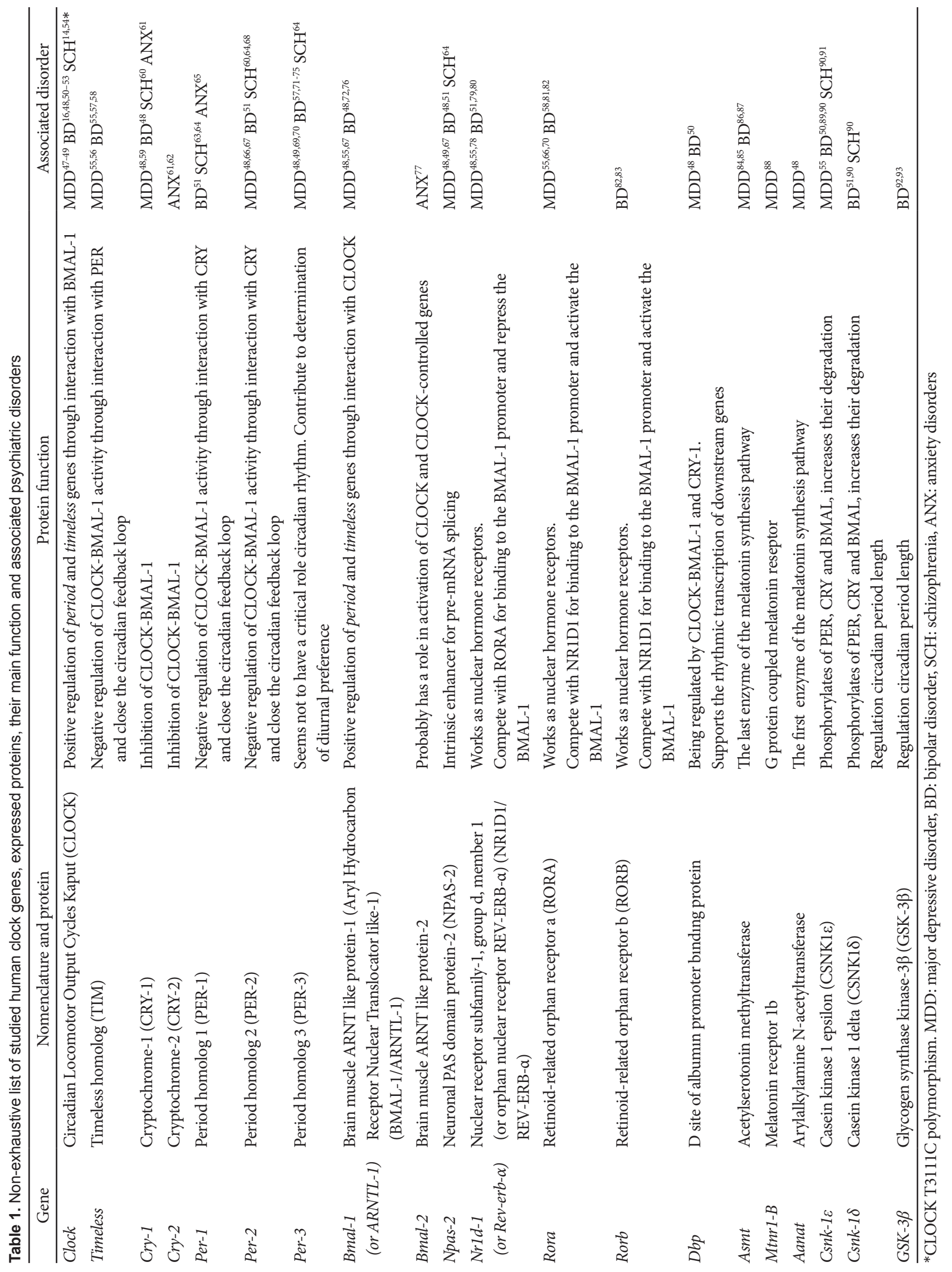


words, melatonin has a modulatory role on the monoaminergic activity by linking the circadian and monoamine systems. The SCN modulates the release of melatonin mainly through $\gamma$-aminobutyric acid (GABA) neurons that project from the SCN to the PVN. ${ }^{113}$ The daylight in the morning and the bright light in the evening activate the SCN neurons that inhibit the same PVN neurons through GABAergic projections and cease the secretion melatonin. ${ }^{32}$ The daily rhythm of melatonin has remarkable effects on the molecular clockworks of both the brain and body alongside regulating the sleep/wake cycle. ${ }^{114,115}$ Melatonin receptors (MT1 and MT2) are mainly localized in the CNS but also have been detected beyond the CNS in a wide range of somatic cells. ${ }^{116}$ This diversity could be interpreted as melatonin having an integrative role in the light-induced circadian rhythms controlled by the SCN in the whole organism.

\section{CIRCADIAN RHYTHM AND ITS IMPLICATIONS ON PSYCHIATRIC DISORDERS}

At the core of any psychiatric disorder is an abnormality in neurotransmitter signaling. It is well known that the disruption of circadian physiology has widespread effects on all aspects of neural and neuroendocrine function, which leads to psychiatric disorders. The aforementioned information regarding neural substrates of biologic rhythm is frequently reported impaired in many mental disorders. Following the comprehen- sive conceptual framework of neural substrates of chronobiologic processes mentioned above, we will next discuss the reciprocal associations between circadian rhythm disturbances and psychiatric disorders, and draw a clinical picture for common diagnoses. Main alterations of sleep architecture are illustrated in Table 2 and major consistent findings in the neurohumoral systems regulating circadian rhythm in psychiatric disorders are summarized in Table 3.

\section{Mood disorders}

In 1681, Robert Burton defined the autumn as the most melancholic season in his best-known classic, The Anatomy of Melancholia. ${ }^{117}$ Circadian rhythm abnormalities in mood disorders have been pointed towards by the observers of melancholia for sixty years. ${ }^{118-120}$ A wide range of body functions such as core body temperature, blood pressure, pulse rate, and hormones such as plasma cortisol levels, thyroid-stimulating hormone, and melatonin have been found disturbed in patients with manic depression and depression compared with people without a mental disorders. ${ }^{119,120}$ Moreover, mood and other symptoms of the disorder have been previously reported to show diurnal variation in depression. ${ }^{121}$ Disordered sleep/wake cycle is considered as another clue for physicians in patients with bipolar disorder (BD) and major depressive disorder (MDD). ${ }^{121}$ In addition, it was recognized that disrupted rhythms were re-synchronized after antidepressant or mood-stabilizing treatment. ${ }^{122}$ Another significant feature is that mood episodes recur season-

Table 2. Main alterations of sleep architecture in psychiatric disorders

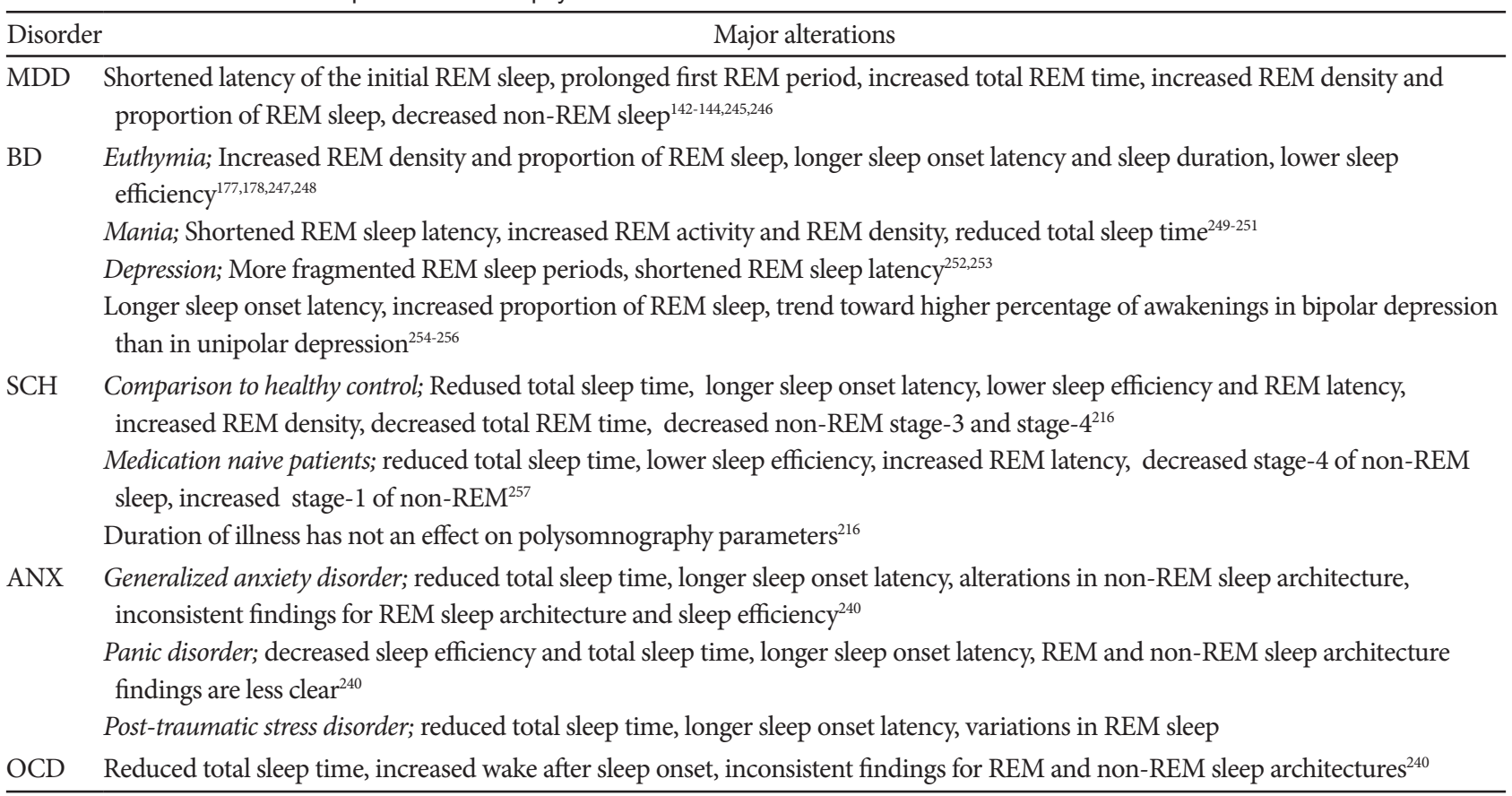
MDD: major depressive disorder, BD: bipolar disorder, SCH: schizophrenia, ANX: anxiety disorders, OCD: obsessive-compulsive disorder, REM: rapid eye movement 
Table 3. Summary of consistent findings on the alterations of two major neurohumoral systems regulating circadian rythm in psychiatric disorders

\begin{tabular}{|c|c|c|}
\hline \multirow{2}{*}{ Diagnosis } & \multicolumn{2}{|c|}{ Neurohumoral system } \\
\hline & HPA axis & Melatonergic system \\
\hline $\mathrm{MDD}$ & $\begin{array}{l}\text { Elevated baseline cortisol levels, disruption on the } \\
\text { dexamethasone suppression test results }{ }^{159,160,258-261} \\
\text { increased cortisol/DHEA ratio }\end{array}$ & $\begin{array}{l}\text { Lower nocturnal melatonin levels, delayed melatonin secretion } \\
\text { onset and offset }{ }^{149,262-278}\end{array}$ \\
\hline $\mathrm{BD}$ & $\begin{array}{l}\text { Increased cortisol and ACTH levels in manic phase } \\
\text { Findings about HPA axis abnormalities are seen both } \\
\text { depressive and euthymic phase, it is preferred to evaluate } \\
\text { them as state and trait marker due to clinical variations }{ }^{199}\end{array}$ & $\begin{array}{l}\text { Higher melatonin levels in manic phase at the daytime }{ }^{186} \\
\text { Findings about nocturnal melatonin levels among } \mathrm{BD} \text { phases are } \\
\text { inconsistent }^{119,188,189,279}\end{array}$ \\
\hline $\mathrm{SCH}$ & $\begin{array}{l}\text { Baseline cortisol levels are inconsistent } \\
\text { Blunted cortisol stress response }{ }^{237}\end{array}$ & $\begin{array}{l}\text { Lower nocturnal melatonin levels, }{ }^{280,281} \text { phase advance in } \\
\text { melatonin rhythm, }{ }^{223} \text { the absence of melatonin rhythmicity }{ }^{282}\end{array}$ \\
\hline
\end{tabular}

MDD: major depressive disorder, BD: bipolar disorder, SCH: schizophrenia, HPA: hypothalamic-pituitary-adrenal, DHEA: dehydroepiandrosterone, ACTH: adrenocorticotropic hormone

ally and previous studies showed that there could be an association between light and the emergence of mood states. ${ }^{123-127}$ Thus, all of these findings suggested the possibility of circadian rhythm disturbance in mood disorders. Consequently, the earliest mention of seasonality took place in the Diagnostic and Statistical Manual of Mental Disorders Third Edition, Revised Version (DSM-III-R), and seasonal pattern was defined as a specifier in the affective disorders section. ${ }^{128}$

Chronotype is another concept associated with mental disorders, particularly with affective disorders, and resembles individual physiologic functions and activities such as sleeping, eating, or hormone release. Chronotype has usually been used to denote sleep habits: morning and evening types. The relationship between chronotypes and several psychiatric disorders has been studied to date and the evening chronotype has been related to a vulnerability to depression and increased alcohol and stimulant drug use. ${ }^{129}$

Although sleep/wake cycle alteration, which is considered as a consequence of circadian system disruption, had been the best-known contributor to the pathophysiology of mood disorders for years, today, it is well-recognized that circadian rhythm is entangled with a wide range of molecular and cellular processes that are hypothesized to lead to mood disorders. ${ }^{130} \mathrm{Ac}$ cordingly, below we discuss in detail internal and external factors that may play a role in the emergence of mood disorders through various psychophysiological mechanisms within the circadian rhythm processes.

\section{Major depressive disorder}

As a cardinal element of chronobiologic processes, sleep behavior and its disturbances have received the strongest spotlight regarding research into their undisputed etiologic and prognostic association with mood disorders. The concomitance of sleep disruption and depression had been the main focus of research into the contribution of circadian rhythms disruption to depression development since the 1970 s. ${ }^{131-133}$ The relationship between sleep and mood could easily be observed even in healthy individuals exposed to jet lag or shiftwork. ${ }^{134}$ The presence of sleep disruption may cause negative effects, irritability, and fatigue. Sleep behavior changes, such as difficulties in initiating/maintaining sleep or early morning awakening have been determined in $90 \%$ of patients with MDD..$^{18}$ Sleepwake disruptions are among the criteria for the diagnosis of depression, and comorbid parasomnias are associated with poor treatment outcomes, increased suicidality, and greater relapse risk in depression. ${ }^{129,135-137}$ Sleep architecture alterations including shortened latency of the initial rapid eye movement (REM) sleep, prolonged first REM period, increased total REM time, increased REM density and proportion of REM sleep, and decreased non-REM sleep have been demonstrated in depression. ${ }^{138-144}$ It has been suggested that there is a reciprocal relationship between sleep-wake cycle variables such as wakefulness and sleep latency and sleep architecture features likes of REM sleep latency. ${ }^{145}$ For instance, preclinical studies have consistently demonstrated that prolonged REM sleep was associated with decreased wakefulness in depressive subjects. ${ }^{146}$ In addition, an endogenous circadian rhythm abnormality, the phase advance, is related to decreased REM latency after falling asleep among individuals with depression. ${ }^{147}$ These findings suggest that sleep itself has multiple and complex regulators related with homeostatic mechanisms along with the endogenous circadian rhythm.

Melatonin output and the timing of its release have been found closely associated with other rhythms as mentioned above. $\mathrm{Nu}$ merous studies have been conducted to show alterations of melatonin release and its phase to determine circadian misalignment between internal and external clocks in patients with mood disorders. ${ }^{148}$ To date, the most consistent results suggested lower nocturnal melatonin levels, delayed melatonin secretion onset, and offset in patients with depression. ${ }^{148} \mathrm{Be}-$ 
sides, the length of the interval between melatonin secretion and sleep onset has been found related to depression severity. ${ }^{149}$ However, a few studies demonstrated increased nocturnal melatonin levels in depressive patients. ${ }^{150}$ Such conflicting findings might be related to the heterogeneity of the study group and inclusion of depressive patients with psychotic symptoms. Abnormal body temperature variations including the absence of the nocturnal decline of core body temperature and daily mean temperature degrees are also observed in patients with depression and these higher values normalized with antidepressant treatment. ${ }^{129,151}$ This is probably due to the impaired control of the melatonergic system over thermoregulatory processes in depressive patients. ${ }^{151,152}$

There is an irrefutable association between circadian genes and mood regulation. Even though mood disorders are not directly related to clock gene mutations, findings suggest that individual genetic polymorphisms of clock genes may influence the clinical features of the disorder, such as age at disease onset and treatment response. ${ }^{47,153}$ Genetic studies have implicated clock, timeless, cryptochrome-1 (Cry-1), period-2,3 (Per2,3), Bmal-1,2, neuronal pas domain protein 2 (Npas-2), nuclear receptor subfamily-1, group d, member 1 (Nr1d-1), retinoid-related orphan receptor a (Rora), CSNK-IE, D site of albumin promoter binding protein (Dbp), acetylserotonin methyltransferase (Asmt), melatonin receptor $1 b$ (Mtnr1-B), arylalkylamine $n$-acetyltransferase (Aanat) genes in unipolar depression. ${ }^{48,66,154-156}$ However, most of these studies have small sample sizes and need to be replicated in larger groups.

Glucocorticoids are adrenal steroid hormones and have multifunctional roles in the body and brain such as metabolism, immunity, arousal, neuronal survival, and neurogenesis. ${ }^{157} \mathrm{Glu}-$ cocorticoids have their own circadian rhythm and an important role in synchronizing peripheral clocks and the SCN. In addition, they have anti-inflammatory properties and regulate the immune system response. ${ }^{158}$ Since Carroll defined the resistance of the dexamethasone suppression test in patients with depression in 1968, ${ }^{159}$ hypothalamic-pituitary-adrenal (HPA) axis dysregulation has been one of the most consistent findings in mental disorders, particularly in depression. ${ }^{130,159}$ Hypercortisolemia-flattened HPA axis circadian rhythm and disrupted response of the HPA axis to glucocorticoid feedback are commonly observed in patients with depression. ${ }^{160,161}$ Dehydroepiandrosterone (DHEA), is another adrenal steroid that has a neuroprotective role and modulates corticosteroid-induced cell death. An increased cortisol/DHEA ratio, which assesses the degree of 'functional' hypercortisolemia, is seen in adults and adolescents with depression. ${ }^{162-164}$ Glucocorticoid receptor hypofunction has also been found in peripheral tissue cells including mononuclear cells and skin cells. ${ }^{165}$ Furthermore, findings support that antidepressant treatment repairs the impaired
HPA axis dysfunction in depression. ${ }^{166}$

Depression and inflammatory disorders such as rheumatoid arthritis, inflammatory bowel disease, and asthma have been found coexisting, and such common comorbidities point to the neuroinflammatory background and immune-associated contributions in the etiopathogenesis of depression. ${ }^{167,168}$ Studies have also shown that pro-inflammatory cytokines could induce a depression-like symptom cluster including anhedonia, fatigue, increased sleep, and decreased locomotor activity. ${ }^{169}$ Inflammatory markers such as interleukin (IL)-1 $\beta$, IL-2, IL-6, tumor necrosis factor (TNF)- $\alpha, C$-reactive protein (CRP), and prostaglandin E2 (PGE2) have been reported increased in patients with depression. ${ }^{170}$ Sleep-wake cycle changes and circadian misalignment between the internal and external clocks may be other contributors to increased pro-inflammatory cytokine levels in depression. The arrhythmic clock system interacts with the nuclear factor-kappa B (NF-kB) signaling pathway, which is one of the major regulators of inflammation in the body and activates the inflammatory response. ${ }^{171,172}$ Besides, sleep disturbances and long sleep duration were found related with the increased cytokines levels and the risk for depression. ${ }^{173}$ We may interpret the aforementioned findings as the circadian system's involvement in the pathophysiology of MDD being not limited to sleep/wake cycle disruption, it is also related to complex associations between biologic rhythm, environmentgene interactions, HPA axis dysfunction, and immune system alterations.

\section{Bipolar disorder}

Sleep disturbances have been the core common characteristic feature in bipolar mood episodes, both mania and depression, since the first definition of Kraepelin. ${ }^{174}$ In turn, insomnia or hypersomnia and decreased need for sleep are typical for manic and depressive episodes. Studies showed that sleep architecture was characterized by increased REM density and reduced REM latency in bipolar manic episodes. ${ }^{175}$ Sleep disturbances are also frequently observed in euthymic patients with $\mathrm{BD}$. Increased REM density and the proportion of REM sleep have been shown in remitted patients with $\mathrm{BD} .{ }^{176}$ Moreover, findings revealed that remitted patients with $\mathrm{BD}$ have longer sleep latency and sleep duration and lower sleep efficiency. ${ }^{177,178}$ Bipolar depression has similar polysomnographic findings including a tendency for more early awakenings and more fragmented REM sleep periods. However, total REM density was found greater in bipolar depression than in unipolar depres$\operatorname{sion}^{176}$ (Table 2). Although abnormalities of sleep architecture are seen in episodes and inter-episodes, sleep disturbances worsen before relapses. Sleep loss and reduced sleep duration were defined as reliable predictors of hypomania and mania. ${ }^{176}$ In addition, hypersomnia in euthymia is found associated with 
the development of upcoming depressive symptoms. ${ }^{179}$ On the other hand, a large amount of euthymic patients describe symptoms that meet the diagnostic criteria for insomnia. ${ }^{178,180}$ Sleep-wake disturbances have been found as one of the reasons for a worse course of illness, relapses, increased symptom severity, and poor treatment outcomes. ${ }^{181-184}$ These findings may explain the reason for the treatment need in remitted patients with BD. ${ }^{136}$

Involvement of the melatonergic system in the pathogenesis of $\mathrm{BD}$ through circadian dysregulations such as changes in the release timing, melatonin rhythm, and the sleep-wake cycle. ${ }^{176}$ In terms of the phase relationship between the sleep-wake cycle and melatonin rhythm, it has been demonstrated that the melatonin secretion in the hours surrounding habitual sleep onset which is considered as a crucial circadian moment for sleep regulation was increased in patients with $\mathrm{BD}$ compared to those with unipolar depression. ${ }^{185}$ Although findings of melatonin function in patients with $\mathrm{BD}$ are inconsistent, circadian system characteristics generally vary depending on the current episode; mania or depression. ${ }^{129}$ Melatonin levels were found higher in the daytime in manic patients than in healthy controls and patients with depressive episode. ${ }^{186}$ Findings about nocturnal melatonin levels among BD phases are not consistent. ${ }^{119,187-189}$ It remains unclear as to whether these alterations derive from a primary dysfunction of the circadian rhythm or if they are secondary to sleep disturbances related to the BD episode. However, some studies supported the beneficial effect of exogenous melatonin administration, which provides sleep and mood improvement. ${ }^{190}$

Some of the clock genes have been found intimately associated with both the onset of $\mathrm{BD}$ and illness course. Studies revealed that circadian gene polymorphisms may increase the predisposition to $\mathrm{BD}$ and indirectly affect recurrences and symptoms across all BD phases. ${ }^{191}$ Genetic linkage and gene expression studies implicated the variant genes related to $\mathrm{BD}$ as clock, timeless, Cry-1, Npas-2, Bmal-1,2, Dbp, Nr1d-1, Per-2,3, Rora,

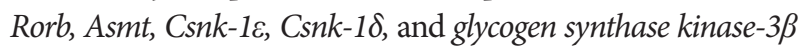
(GSK-3ß)..$^{51,83,86,155,191,192}$ It has been demonstrated that ClockD19, the mutant gene that occurs with the deletion of exon 19 in the Clock gene, produces a dominant negative CLOCK protein capable of DNA binding but deficient in transcriptional activity. This gene induces dopamine synthesis and increased dopaminergic activity, which result in an increase in tyrosine hydroxylase (TH) expression in the ventral tegmental area (VTA) and manic-like behavior in animal models. ${ }^{193-195}$ Moreover, ClockD19related higher dopaminergic activity in the VTA normalized after lithium treatment, which suggests increased dopaminergic activity may be the main reason for the manic-like behavior of mice. ${ }^{195}$ Recently, several lines of evidence have emphasized the importance of the molecular and synaptic mechanisms of monoaminergic systems and circadian gene interactions, which are closely related to molecular alterations associated with the ClockD19 model in the VTA and nucleus accumbens. ${ }^{196}$ On the other hand, lithium, a potent inhibitor of the GSK-3 enzyme, regulates the clock gene Nr1d-1 and BMAL-1 through GSK-3. ${ }^{197}$ Some polymorphisms including Clockrs3805148, Clockrs534654, Timelessrs11171856, and Timelessrs2291739 are associated with suicidal behavior in BD. ${ }^{198}$

A dysfunctional HPA axis is suggested to play an important role in the pathophysiology of $\mathrm{BD}$, although the mechanism needs to be elucidated. Increased levels of cortisol and ACTH are the most replicated findings in BD. ${ }^{199,200}$ However, CRH levels are not determined to increase in $\mathrm{BD} .{ }^{199}$ Depressive symptoms and cognitive deficits are thought to be associated with the higher levels of cortisol, and ACTH and cortisol seem to be related to manic episodes. ${ }^{200} \mathrm{~A}$ meta-analysis suggested that abnormalities of stress-related pathways including increased morning cortisol levels were mainly prominent in manic episodes. Such abnormalities are even observed in remitted patients, which means that the long-term pathology of the HPA axis is related to clinical states of $\mathrm{BD}$ and contributes to the stress-vulnerability models of illness development and progression. ${ }^{201}$

Immune abnormalities have received increased attention due to their possible role in the pathophysiology of $\mathrm{BD}$, as well as MDD. Systematic reviews on cytokine levels in patients with BD revealed that IL-4, IL-6, IL-10, soluble IL-2 receptor, soluble IL-6 receptor, and TNF- $\alpha$ levels were increased in patients compared with healthy controls, whereas IL-2, IL-8, IFN-gam$\mathrm{ma}$, and C-C motif ligand were not different from controls. ${ }^{202}$ Moreover, a comparison of cytokine levels in another study determined that proinflammatory cytokines including IL-2, IL-4, IL-6 were higher during manic episodes, and IL-6 levels were higher in depressive state than in healthy controls. ${ }^{203}$ It was also demonstrated that mood symptoms had a positive correlation with IL- 6 and IL-2 levels. ${ }^{203}$ When bipolar depression and unipolar depression were compared, sIL-6R, CRP, sTNF-R1, and monocyte chemoattractant protein-1 (MCP-1) were found at higher levels than in unipolar depression. ${ }^{204} \mathrm{In}$ conclusion, sleep disturbances may be a reliable indicator of an upcoming mood episode in $\mathrm{BD}$.

\section{Schizophrenia}

Although the relationship between mood disorders and circadian abnormalities has become clearer in recent times, the links between schizophrenia and disrupted circadian rhythms have yet to be elucidated fully. However, sleep disorders and sleep-wake cycle alterations have been known as common and consistent features of schizophrenia and other psychotic disorders since the first definition of Kraepelin in $1883 .{ }^{205}$ Schizophrenia has been associated with abnormalities in sleep includ- 
ing delayed and advanced sleep onset, altered resting activity patterns, and irregular sleep-wake cycle. ${ }^{206}$ Research into circadian abnormalities and sleep disruption in schizophrenia has attempted to explain the causal relationship in a reciprocal context. Hyperdopaminergia is a well-known phenomenon in psychosis syndromes and striatal hyperdopaminergic activity may be a result of sleep disruption and circadian abnormalities, and increased dopamine levels may induce sleep disruptions. ${ }^{207-209}$ For instance, the Clock T3111C polymorphism, which is associated with increased dopamine levels in the SCN, has been determined in a population of Japanese patients with schizophrenia. ${ }^{14}$ Furthermore, the blind-drunk mutant mouse, which carries a mutation in the gene encoding an exocytotic synaptic protein, synaptosomal-associated protein-25 (Snap-25), exhibits schizophrenia-like symptoms. ${ }^{210,211}$ This mouse model of schizophrenia has been shown to display phase advance and fragmentation of the circadian cycle. ${ }^{212}$ Most consistent findings of the circadian genetics studies have been associations between CLOCK, PERIOD1, PERIOD3, and TIMELESS genes and schizophrenia. ${ }^{213}$ Circadian rhythms disruption has been reported in approximately $80 \%$ of patients with schizophrenia. ${ }^{214}$ Abnormal sleep patterns in schizophrenia have been described in both unmedicated patients and patients currently receiving antipsychotic treatment. ${ }^{18}$ The major findings in sleep architecture could be aligned, such as long sleep-onset latency, increased intermittent-awakenings, decreased total sleep time, and poor sleep efficiency. ${ }^{215}$ Moreover, reductions in REM latency, REM density, and duration of non-REM Stage 4 are other alterations in micro-sleep architecture. ${ }^{17,18,216-218}$ Sleep disturbances are also important to predict increased suicide attempts in patients with schizophrenia. ${ }^{219}$

Melatonin is a versatile neurohormone that plays an important role in the pathophysiology of schizophrenia. 5-HT synthesis regulation, sleep-wake cycle, and anti-oxidant effects against neuroinflammation are impaired due to melatonin dysfunction in schizophrenia. ${ }^{208,220}$ It has been shown that melatonin increases endogenous antioxidants by increasing phosphorylated glycogen synthase kinase-3 (GSK-3) levels and provides an anti-inflammatory effect. ${ }^{220,221}$ Galván-Arrieta et al. ${ }^{222}$ reported a reduction in axogenesis associated with lower levels of phosphorylated GSK-3 subtype $\beta$ and less expression of melatonergic receptors in patients with schizophrenia compared with healthy controls. These findings may indicate a melatonin-derived neurodevelopmental deficit at a cellular level. A lack of normal melatonin rhythmicity, decreased nocturnal secretion of melatonin, and phase advance in melatonin circadian rhythms have also been described in patients with schizophrenia. ${ }^{208,220,223}$ Additionally, pineal calcification in computed tomography has been demonstrated in patients with schizophrenia, and this structural change has been found associat- ed with cortical atrophy. ${ }^{224}$ Mainly, the clinical importance of the relationship schizophrenia and melatonergic dysfunction might come from the fact that impairment of sleep-wake cycles which are in close relationship with melatonin phase are associated with schizophrenia symptoms such as somatic complaints, anxiety, depression, and paranoia. Further support has shown that sleep-deprived schizophrenia patients might exhibit increased psychotic symptoms. ${ }^{208}$ Moreover, the circadian rhythm of dopamine is dependent on melatonin. ${ }^{225} \mathrm{~A}$ combination of sleep disruption and circadian rhythms disturbance may lead to the elevation of dopamine activity in the brain, both directly and through phase advance in melatonin circadian rhythm. ${ }^{208}$ Preclinical studies have been also demonstrated that melatonergic receptor agonism may prevent the increase of glutamate release in prefrontal cortex, ${ }^{226}$ which has been suggested in the pathophysiology of schizophrenia, particularly of cognitive symptoms of the disorder. ${ }^{227}$ Because of its significance in the pathogenesis of schizophrenia, melatonin has become a therapeutic target for researchers. It has been shown that melatonin agonists are efficacious agents for schizophrenia-associated sleep disorders and drug-related tardive dyskinesia. ${ }^{228,229}$ Moreover, its improving effects on behavioral deficits via reducing brain oxidative stress have been shown in an animal model of schizophrenia. ${ }^{230}$

The relationship between clock genes and schizophrenia is another undiscovered area for scientists. Few studies have been conducted to show linking circadian clock gene polymorphisms in schizophrenia to date. Takao et al. ${ }^{14}$ identified the Clock $311 \mathrm{C} / \mathrm{T}$ polymorphism, which is associated with higher dopaminergic neurotransmission in the SCN in patients with schizophrenia. These results were confirmed in another study conducted in a Chinese schizophrenic population. ${ }^{54}$ Period-1 mRNA expression in the temporal lobe of post-mortem subjects with schizophrenia was found down-regulated when compared with healthy controls. ${ }^{63}$ In addition, disrupted diurnal rhythms of the Per-1, Per-2, Per-3, Npas-2 and phase delay in the expression of Per-2 have been reported in white blood cells of patients with schizophrenia. ${ }^{64}$ More recently, the absence of rhythmic expression of Cry-1 and Per-2 was determined in the fibroblasts of patients with schizophrenia compared with cells obtained from healthy controls. ${ }^{60}$ Pinacho et al. ${ }^{91}$ reported decreased levels of CSNK1 $1 \varepsilon$ protein levels in the prefrontal cortex of patients with schizophrenia. However, due to the small sample sizes of the available studies, the association between schizophrenia and clock genes still needs to be clarified with further studies with larger populations.

The stress-vulnerability model for schizophrenia was first proposed in the 1970s and has been further developed since that time. ${ }^{231,232}$ Thus, the HPA axis has been one of the most attractive research targets to understand the pathophysiology 
of schizophrenia for decades. Increased cortisol levels have been determined in patients with schizophrenia and even in individuals at high risk for schizophrenia compared with controls. ${ }^{233-235}$ However, mean baseline cortisol level measurements in schizophrenia are not consistent in the literature. ${ }^{236}$ Nevertheless, blunted cortisol levels in response to stressors are much more consistent findings, regardless of disease stage, chronicity, and treatment condition. ${ }^{237}$ To conclude, despite it being widely accepted that sleep and circadian disorders have an important role in the etiopathogenesis of schizophrenia, well-designed and comprehensive clinical studies are still needed to explicate the genetic and neurobiologic underpinnings.

\section{Other psychiatric disorders}

Anxiety disorders are seen as the most frequent type of psychiatric disorders with a lifetime prevalence of $29 \%$ in the general population. ${ }^{238}$ Sleep disturbance is a common feature of anxiety disorders and is included in the symptom criteria for several anxiety disorders such as post-traumatic stress disorder and generalized anxiety disorder. ${ }^{239}$ The presence of sleep disturbances has been reported as $74 \%$ in patients with anxiety disorders. ${ }^{176}$ However, MDD as a frequent comorbid condition in anxiety disorders is a confounder in understanding the relationship of sleep disturbances and anxiety disorders. Studies related to generalized anxiety disorder have reported decreased total sleep time, increased sleep-onset latency, and alterations in non-REM sleep architecture, whereas findings of REM sleep and sleep efficiency are inconsistent. ${ }^{240}$ Patients with panic disorder frequently have both sleep disorder and/or another anxiety disorder because they could have nocturnal panic attacks, which usually occur in Stage-2 or Stage- 3 of non-REM sleep, as well as decreased sleep efficiency, total sleep time, and increased sleep onset latency. ${ }^{176,240}$ Although sleep disturbances, including REM sleep-related nightmares, have been investigated in post-traumatic stress disorder, conclusions are not consistent. ${ }^{176}$ There is no significant difference in sleep architecture in social anxiety disorder. ${ }^{241,242}$ In an animal model, Cry-1 and Cry-2 gene protein deficiencies led to behavioral alterations characterized by an abnormally high level of anxiety. ${ }^{61}$ Akiyama et al. ${ }^{65}$ suggested that period-1 mRNA levels reduced after anti-anxiety treatment in the mouse cerebellum. Cry-2 expression was determined reduced in the hippocampus in another animal study. ${ }^{62}$ Furthermore, a polymorphism in $B M A L-2 r s 2306073$ has been found associated with social phobia. $^{77}$

Obsessive-compulsive disorder (OCD) is another debilitating disorder that is segregated from the anxiety disorders category in the DSM-5. ${ }^{243}$ Although sleep disturbances have been reported including decreased total sleep time, alterations in REM and non-REM sleep architecture are less clear. ${ }^{240}$ Cer- tain chronotypes have been found as predictors of OCD symptoms in adults, and circadian rhythm disorders have been found as predictors of treatment outcomes. ${ }^{244}$ To the best of our knowledge, the role of circadian rhythms disruption in all anxiety disorders, including OCD, has yet to go beyond showing sleep disturbance; comprehensive research is warranted in the context of chronobiologic mechanisms of anxiety disorder pathology.

\section{CONCLUSION}

The circadian system is responsible for the temporal organization of physiologic functions, and disruptions can have marked functional influences on the living organism. As the role of chronobiologic systems in both physical and mental health have become better understood, research into neurobiologic mechanisms of circadian rhythms has been expanded. Mood, cognition, and behavior have complex relationships with biologic rhythms, and the vast majority of mental disorders are reciprocally associated with impaired circadian biology. Extensive research has shown that impaired circadian mechanisms could lead to psychiatric entities, whereas they may be an outcome of mental disturbances. Impaired HPA axis function and melatonin homeostasis are the most consistent findings in mental disorders. Independent from sleep disorders, the circadian system has a distinct role in homeostatic processes, whose impairment has an impact in emotion regulation, cognition, behavior, and, most importantly, neural plasticity, all of which are often disrupted in psychiatric phenotypes. There is some evidence suggesting that circadian rhythm genes are associated with psychiatric disorders; however, the specificity and causality of these associations have yet to be made clear. In our opinion, we are a long way from establishing a robust causative link between circadian rhythms disruption and phenotypic complexity of psychiatric disorders. A decent translational approach to the findings of animal models would likely result in a clearer understanding of pathophysiologic implications of the circadian system. Further support from continued and integrated investigations of these issues may promote a deeper appreciation of the contribution of circadian disturbances to the pathophysiology of psychiatric illnesses and related psychopathology, and will hopefully yield improved therapeutic strategies for their treatment.

\section{Acknowledgments}

None.

\section{Conflicts of Interest}

The authors have no potential conflicts of interest to disclose. 


\section{Author Contributions}

Conceptualization: Simge Seren Kirlioglu, Yasin Hasan Balcioglu. Data curation: Simge Seren Kirlioglu. Methodology: Simge Seren Kirlioglu, Yasin Hasan Balcioglu. Supervision: Yasin Hasan Balcioglu. Visualization: Simge Seren Kirlioglu. Writing —original draft: Simge Seren Kirlioglu. Writing_review \& editing: Yasin Hasan Balcioglu.

\section{ORCID iDs}

Simge Seren Kirlioglu

Yasin Hasan Balcioglu https://orcid.org/0000-0001-9778-6617

https://orcid.org/0000-0002-1336-1724

\section{REFERENCES}

1. Foster RG, Kreitzman L. Rhythms of Life: The Biological Clocks that Control the Daily Lives of Every Living Thing. New Haven (Connecticut): Yale University Press; 2005.

2. Halberg F, Cornélissen G, Katinas G, Syutkina EV, Sothern RB, Zaslavskaya $\mathrm{R}$, et al. Transdisciplinary unifying implications of circadian findings in the 1950s. J Circadian Rhythms 2003;1:2.

3. Konopka RJ, Benzer S. Clock mutants of Drosophila melanogaster. Proc Natl Acad Sci U S A 1971;68:2112-2116.

4. Bargiello TA, Jackson FR, Young MW. Restoration of circadian behavioural rhythms by gene transfer in Drosophila. Nature 1984;312: 752-754.

5. Reddy P, Zehring WA, Wheeler DA, Pirrotta V, Hadfield C, Hall JC, et al. Molecular analysis of the period locus in Drosophila melanogaster and identification of a transcript involved in biological rhythms. Cell 1984;38:701-710.

6. Huang RC. The discoveries of molecular mechanisms for the circadian rhythm: the 2017 Nobel Prize in Physiology or Medicine. Biomed J 2018;41:5-8.

7. Crosby EC, Woodburne RT. The mammalian midbrain and isthmus regions. Part II. The fiber connections. C. The hypothalamo-tegmental pathways. J Comp Neurol 1951;94:1-32.

8. Sollars PJ, Pickard GE. The neurobiology of circadian rhythms. Psychiatr Clin North Am 2015;38:645-665.

9. Zhu L, Zee PC. Circadian rhythm sleep disorders. Neurol Clin 2012; 30:1167-1191.

10. Gillette M. Chronobiology: Biological Timing in Health and Disease. Progress in Molecular Biology and Translational Science Vol: 119. Boston: Elsevier; 2013.

11. Dijk DJ, Duffy JF, Czeisler CA. Contribution of circadian physiology and sleep homeostasis to age- related changes in human sleep. Chronobiol Int 2000;17:285-311.

12. Panda S. Circadian physiology of metabolism. Science 2016;354:10081015.

13. Baron KG, Reid KJ. Circadian misalignment and health. Int Rev Psychiatry 2014;26:139-154.

14. Takao T, Tachikawa H, Kawanishi Y, Mizukami K, Asada T. CLOCK gene T3111C polymorphism is associated with Japanese schizophrenics: a preliminary study. Eur Neuropsychopharmacol 2007;17:273-276.

15. Benedetti F, Serretti A, Colombo C, Barbini B, Lorenzi C, Campori E, et al. Influence ofCLOCK gene polymorphism on circadian mood fluctuation and illness recurrence in bipolar depression. Am J Med Genet B Neuropsychiatr Genet 2003;123B:23-26.

16. Lee KY, Song JY, Kim SH, Kim SC, Joo EJ, Ahn YM, et al. Association between CLOCK 3111T/C and preferred circadian phase in Korean patients with bipolar disorder. Prog Neuro-Psychopharmacology Biol Psychiatry 2010;34:1196-1201.

17. Jones SG, Benca RM. Circadian disruption in psychiatric disorders. Sleep Med Clin 2015;10:481-493.

18. Wulff K, Gatti S, Wettstein JG, Foster RG. Sleep and circadian rhythm disruption in psychiatric and neurodegenerative disease. Nat Rev Neurosci 2010;11:589-599.
19. Hardin PE, Hall JC, Rosbash M. Feedback of the Drosophila period gene product on circadian cycling of its messenger RNA levels. Nature 1990;343:536-540.

20. Gekakis N, Saez L, Delahaye-Brown AM, Myers MP, Sehgal A, Young MW, et al. Isolation of timeless by PER protein interaction: defective interaction between timeless protein and long-period mutant PERL. Science 1995;270:811-815.

21. Allada R, White NE, So WV, Hall JC, Rosbash M. A mutant drosophila homolog of mammalian clock disrupts circadian rhythms and transcription of period and timeless. Cell 1998;93:791-804.

22. Rutila JE, Suri V, Le M, So WV, Rosbash M, Hall JC. CYCLE Is a second bHLH-PAS clock protein essential for circadian rhythmicity and transcription of drosophila period and timeless. Cell 1998;93:805-814.

23. Price JL, Blau J, Rothenfluh A, Abodeely M, Kloss B, Young MW. Double-time is a novel drosophila clock gene that regulates PERIOD protein accumulation. Cell 1998;94:83-95.

24. Kloss B, Price JL, Saez L, Blau J, Rothenfluh A, Wesley CS, et al. The drosophila clock gene double-time encodes a protein closely related to human casein kinase Iepsilon. Cell 1998;94:97-107.

25. Lowrey PL, Shimomura K, Antoch MP, Yamazaki S, Zemenides PD, Ralph MR, et al. Positional syntenic cloning and functional characterization of the mammalian circadian mutation tau. Science 2000;288: 483-492.

26. Mohawk JA, Green CB, Takahashi JS. Central and peripheral circadian clocks in mammals. Annu Rev Neurosci 2012;35:445-462.

27. Challet E. Keeping circadian time with hormones. Diabetes Obes Metab 2015;17:76-83.

28. Colwell CS. Linking neural activity and molecular oscillations in the SCN. Nat Rev Neurosci 2011;12:553-569.

29. Tsang AH, Astiz M, Friedrichs M, Oster H. Endocrine regulation of circadian physiology. J Endocrinol 2016;230:R1-R11.

30. Mrosovsky N, Hattar S. Impaired masking responses to light in melanopsin-knockout mice. Chronobiol Int 2003;20:989-999.

31. Dibner C, Schibler U, Albrecht U. The mammalian circadian timing system: organization and coordination of central and peripheral clocks. Annu Rev Physiol 2010;72:517-549.

32. Pevet P, Challet E. Melatonin: both master clock output and internal time-giver in the circadian clocks network. J Physiol 2011;105:170-182.

33. Hankins MW, Peirson SN, Foster RG. Melanopsin: an exciting photopigment. Trends Neurosci 2008;31:27-36.

34. Amaral FGD, Cipolla-Neto J. A brief review about melatonin, a pineal hormone. Arch Endocrinol Metab 2018;62:472-479.

35. Asher G, Sassone-Corsi P. Time for food: the intimate interplay between nutrition, metabolism, and the circadian clock. Cell 2015;161: 84-92.

36. Buijs FN, Cazarez F, Basualdo MC, Scheer FAJL, Perusquía M, Centurion $\mathrm{D}$, et al. The suprachiasmatic nucleus is part of a neural feedback circuit adapting blood pressure response. Neuroscience 2014;266:197207.

37. Pfeffer M, Wicht H. Synchronizing effects of melatonin on diurnal and circadian rhythms. Gen Comp Endocrinol 2018;258:215-221.

38. Sabbar M, Dkhissi-Benyahya O, Benazzouz A, Lakhdar-Ghazal N. Circadian clock protein content and daily rhythm of locomotor activity are altered after chronic exposure to lead in rat. Front Behav Neurosci 2017;11:178.

39. Zhang T, Huang L, Zhang L, Tan M, Pu M, Pickard GE, et al. ON and OFF retinal ganglion cells differentially regulate serotonergic and GABAergic activity in the dorsal raphe nucleus. Sci Rep 2016;6:26060.

40. Robillard R, Carpenter JS, Feilds KL, Hermens DF, White D, Naismith SL, et al. Parallel changes in mood and melatonin rhythm following an adjunctive multimodal chronobiological intervention with agomelatine in people with depression: a proof of concept open label study. Front Psychiatry 2018;9:624.

41. Duval F, Mokrani MC, Erb A, Gonzalez opera F, Calleja C, Paris V. Relationship between chronobiological thyrotropin and prolactin re- 
sponses to protirelin (TRH) and suicidal behavior in depressed patients. Psychoneuroendocrinology 2017;85:100-109.

42. Robillard R, Carpenter JS, Rogers NL, Fares S, Grierson AB, Hermens DF, et al. Circadian rhythms and psychiatric profiles in young adults with unipolar depressive disorders. Transl Psychiatry 2018;8:213.

43. Buttgereit F, Smolen JS, Coogan AN, Cajochen C. Clocking in: chronobiology in rheumatoid arthritis. Nat Rev Rheumatol 2015;11:349356.

44. Saetung S, Nimitphong H, Siwasaranond N, Manodpitipong A, Crowley SJ, Hood MM, et al. Eveningness is associated with greater depressive symptoms in type 2 diabetes patients: a study in two different ethnic cohorts. Behav Sleep Med 2019;17:291-301.

45. Charrier A, Olliac B, Roubertoux P, Tordjman S, Charrier A, Olliac B, et al. Clock genes and altered sleep-wake rhythms: their role in the development of psychiatric disorders. Int J Mol Sci 2017;18:938.

46. Barandas R, Landgraf D, McCarthy MJ, Welsh DK. Circadian clocks as modulators of metabolic comorbidity in psychiatric disorders. Curr Psychiatry Rep 2015;17:98.

47. Kishi T, Kitajima T, Ikeda M, Yamanouchi Y, Kinoshita Y, Kawashima $\mathrm{K}$, et al. CLOCK may predict the response to fluvoxamine treatment in Japanese major depressive disorder patients. NeuroMolecular Med 2009;11:53-57.

48. Soria V, Martínez-Amorós Ė, Escaramís G, Valero J, Pérez-Egea R, García C, et al. Differential association of circadian genes with mood disorders: CRY1 and NPAS2 are associated with unipolar major depression and CLOCK and VIP with bipolar disorder. Neuropsychopharmacology 2010;35:1279-1289.

49. Shi S, White MJ, Borsetti HM, Pendergast JS, Hida A, Ciarleglio CM, et al. Molecular analyses of circadian gene variants reveal sex-dependent links between depression and clocks. Transl Psychiatry 2016;6: e748-e748.

50. Shi J, Wittke-Thompson JK, Badner JA, Hattori E, Potash JB, Willour $\mathrm{VL}$, et al. Clock genes may influence bipolar disorder susceptibility and dysfunctional circadian rhythm. Am J Med Genet Part B Neuropsychiatr Genet 2008;147B:1047-1055.

51. Kripke DF, Nievergelt CM, Joo EJ, Shekhtman T, Kelsoe JR. Circadian polymorphisms associated with affective disorders. J Circadian Rhythms 2009;7:2.

52. Suzuki M, Dallaspezia S, Locatelli C, Lorenzi C, Uchiyama M, Colombo $\mathrm{C}$, et al. CLOCK gene variants associated with the discrepancy between subjective and objective severity in bipolar depression. J Affect Disord 2017;210:14-18.

53. Benedetti F, Riccaboni R, Dallaspezia S, Locatelli C, Smeraldi E, Colombo C. Effects of CLOCK gene variants and early stress on hopelessness and suicide in bipolar depression. Chronobiol Int 2015;32: 1156-1161.

54. Zhang J, Liao G, Liu C, Sun L, Liu Y, Wang Y, et al. The association of CLOCK gene T3111C polymorphism and hPER3 gene 54-nucleotide repeat polymorphism with Chinese Han people schizophrenics. Mol Biol Rep 2011;38:349-354.

55. Utge SJ, Soronen P, Loukola A, Kronholm E, Ollila HM, Pirkola S, et al. Systematic analysis of circadian genes in a population-based sample reveals association of TIMELESS with depression and sleep disturbance. PLoS One 2010;5:e9259.

56. Dmitrzak-Weglarz MP, Pawlak JM, Maciukiewicz M, Moczko J, Wilkosc M, Leszczynska-Rodziewicz A, et al. Clock gene variants differentiate mood disorders. Mol Biol Rep 2015;42:277-288.

57. Mansour HA, Wood J, Logue T, Chowdari K V., Dayal M, Kupfer DJ, et al. Association study of eight circadian genes with bipolar I disorder, schizoaffective disorder and schizophrenia. Genes Brain Behav 2006; 5:150-157.

58. Etain B, Jamain S, Milhiet V, Lajnef M, Boudebesse C, Dumaine A, et al. Association between circadian genes, bipolar disorders and chronotypes. Chronobiol Int 2014;31:807-814.

59. Hua P, Liu W, Chen D, Zhao Y, Chen L, Zhang N, et al. Cryl and Tef gene polymorphisms are associated with major depressive disorder in the Chinese population. J Affect Disord 2014;157:100-103.

60. Johansson A-S, Owe-Larsson B, Hetta J, Lundkvist GB. Altered circadian clock gene expression in patients with schizophrenia. Schizophr Res 2016;174:17-23.

61. De Bundel D, Gangarossa G, Biever A, Bonnefont X, Valjent E. Cognitive dysfunction, elevated anxiety, and reduced cocaine response in circadian clock-deficient cryptochrome knockout mice. Front Behav Neurosci 2013;7:152.

62. Griesauer I, Diao W, Ronovsky M, Elbau I, Sartori S, Singewald N, et al. Circadian abnormalities in a mouse model of high trait anxiety and depression. Ann Med 2014;46:148-154.

63. Aston C, Jiang L, Sokolov BP. Microarray analysis of postmortem temporal cortex from patients with schizophrenia. J Neurosci Res 2004;77:858-866.

64. Sun HQ, Li SX, Chen FB, Zhang Y, Li P, Jin M, et al. Diurnal neurobiological alterations after exposure to clozapine in first-episode schizophrenia patients. Psychoneuroendocrinology 2016;64:108-116.

65. Akiyama M, Kirihara T, Takahashi S, Minami Y, Yoshinobu Y, Moriya $\mathrm{T}$, et al. Modulation of mPer1 gene expression by anxiolytic drugs in mouse cerebellum. Br J Pharmacol 1999;128:1616-1622.

66. Lavebratt C, Sjöholm LK, Partonen T, Schalling M, Forsell Y. PER2 variantion is associated with depression vulnerability. Am J Med Genet Part B Neuropsychiatr Genet 2010;153:570-581.

67. Partonen T, Treutlein J, Alpman A, Frank J, Johansson C, Depner M, et al. Three circadian clock genes Per2, Arntl, and Npas2 contribute to winter depression. Ann Med 2007;39:229-238.

68. Liu JJ, Sudic Hukic D, Forsell Y, Schalling M, Ösby U, Lavebratt C. Depression-associated ARNTL and PER2 genetic variants in psychotic disorders. Chronobiol Int 2015;32:579-584.

69. Artioli P, Lorenzi C, Pirovano A, Serretti A, Benedetti F, Catalano M, et al. How do genes exert their role? Period 3 gene variants and possible influences on mood disorder phenotypes. Eur Neuropsychopharmacol 2007;17:587-594.

70. Maglione JE, Nievergelt CM, Parimi N, Evans DS, Ancoli-Israel S, Stone KL, et al. Associations of PER3 and RORA circadian gene polymorphisms and depressive symptoms in older adults. Am J Geriatr Psychiatry 2015;23:1075-1087.

71. Brasil Rocha PM, Campos SB, Neves FS, da Silva Filho HC. Genetic association of the PERIOD3 (Per3) clock gene with bipolar disorder. Psychiatry Investig 2017;14:674-680.

72. Nievergelt CM, Kripke DF, Barrett TB, Burg E, Remick RA, Sadovnick $\mathrm{AD}$, et al. Suggestive evidence for association of the circadian genes PERIOD3 and ARNTL with bipolar disorder. Am J Med Genet Part B Neuropsychiatr Genet 2006;141B:234-241.

73. Benedetti F, Dallaspezia S, Colombo C, Pirovano A, Marino E, Smeraldi E. A length polymorphism in the circadian clock gene Per3 influences age at onset of bipolar disorder. Neurosci Lett 2008;445:184187.

74. Dallaspezia S, Lorenzi C, Pirovano A, Colombo C, Smeraldi E, Benedetti F. Circadian clock gene Per3 variants influence the postpartum onset of bipolar disorder. Eur Psychiatry 2011;26:138-140.

75. Karthikeyan R, Marimuthu G, Ramasubramanian C, Arunachal G, BaHammam AS, Spence DW, et al. Association of Per3 length polymorphism with bipolar I disorder and schizophrenia. Neuropsychiatr Dis Treat 2014;10:2325-2330.

76. Bengesser SA, Reininghaus EZ, Lackner N, Birner A, Fellendorf FT, Platzer $\mathrm{M}$, et al. Is the molecular clock ticking differently in bipolar disorder? Methylation analysis of the clock gene ARNTL. World J Biol Psychiatry 2018;19:S21-S29.

77. Sipilä T, Kananen L, Greco D, Donner J, Silander K, Terwilliger JD, et al. An association analysis of circadian genes in anxiety disorders. Biol Psychiatry 2010;67:1163-1170.

78. Byrne EM, Heath AC, Madden PAF, Pergadia ML, Hickie IB, Montgomery GW, et al. Testing the role of circadian genes in conferring risk 
for psychiatric disorders. Am J Med Genet Part B Neuropsychiatr Genet 2014;165:254-260.

79. Severino G, Manchia M, Contu P, Squassina A, Lampus S, Ardau R, et al. Association study in a Sardinian sample between bipolar disorder and the nuclear receptor REV-ERB $a$ gene, a critical component of the circadian clock system. Bipolar Disord 2009;11:215-220.

80. Kishi T, Kitajima T, Ikeda M, Yamanouchi Y, Kinoshita Y, Kawashima $\mathrm{K}$, et al. Association analysis of nuclear receptor Rev-erb alpha gene (NR1D1) with mood disorders in the Japanese population. Neurosci Res 2008;62:211-215.

81. Geoffroy PA, Etain B, Lajnef M, Zerdazi E-H, Brichant-Petitjean C, Heilbronner $\mathrm{U}$, et al. Circadian genes and lithium response in bipolar disorders: associations with PPARGC1A (PGC-1 $\alpha$ ) and RORA. Genes Brain Behav 2016;15:660-668.

82. Lai YC, Kao CF, Lu ML, Chen HC, Chen PY, Chen CH, et al. Investigation of associations between NR1D1, RORA and RORB genes and bipolar disorder. PLoS One 2015;10:e0121245.

83. McGrath CL, Glatt SJ, Sklar P, Le-Niculescu H, Kuczenski R, Doyle $\mathrm{AE}$, et al. Evidence for genetic association of RORB with bipolar disorder. BMC Psychiatry 2009;9:70.

84. Gałecki P, Szemraj J, Bartosz G, Bieńkiewicz M, Gałecka E, Florkowski A, et al. Single-nucleotide polymorphisms and mRNA expression for melatonin synthesis rate-limiting enzyme in recurrent depressive disorder. J Pineal Res 2010;48:311-317.

85. Talarowska M, Szemraj J, Zajączkowska M, Gałecki P. ASMT gene expression correlates with cognitive impairment in patients with recurrent depressive disorder. Med Sci Monit 2014;20:905-912.

86. Geoffroy PA, Boudebesse C, Henrion A, Jamain S, Henry C, Leboyer $\mathrm{M}$, et al. An ASMT variant associated with bipolar disorder influences sleep and circadian rhythms: a pilot study. Genes Brain Behav 2014; 13:299-304.

87. Etain B, Dumaine A, Bellivier F, Pagan C, Francelle L, Goubran-Botros $\mathrm{H}$, et al. Genetic and functional abnormalities of the melatonin biosynthesis pathway in patients with bipolar disorder. Hum Mol Genet 2012;21:4030-4037.

88. Gałecka E, Szemraj J, Florkowski A, Gałecki P, Bieńkiewicz M, Karbownik-Lewińska M, et al. Single nucleotide polymorphisms and mRNA expression for melatonin MT2 receptor in depression. Psychiatry Res 2011;189:472-474.

89. Lee KY, Ahn YM, Kim SH, Kang HG, Joo EJ. Genetic association study of CSNK1E gene in bipolar disorder and circadian characteristics. Nord J Psychiatry 2018;72:599-604.

90. Matsunaga S, Ikeda M, Kishi T, Fukuo Y, Aleksic B, Yoshimura R, et al. An evaluation of polymorphisms in casein kinase 1 delta and epsilon genes in major psychiatric disorders. Neurosci Lett 2012;529:6669.

91. Pinacho R, Villalmanzo N, Meana JJ, Ferrer I, Berengueras A, Haro JM, et al. Altered CSNK1E, FABP4 and NEFH protein levels in the dorsolateral prefrontal cortex in schizophrenia. Schizophr Res 2016; 177:88-97.

92. Kaladchibachi SA, Doble B, Anthopoulos N, Woodgett JR, Manoukian AS. Glycogen synthase kinase 3, circadian rhythms, and bipolar disorder: a molecular link in the therapeutic action of lithium. J Circadian Rhythms 2007;5:3.

93. Szczepankiewicz A, Skibinska M, Hauser J, Slopien A, LeszczynskaRodziewicz A, Kapelski P, et al. Association analysis of the GSK-3beta T-50C gene polymorphism with schizophrenia and bipolar disorder. Neuropsychobiology 2006;53:51-56.

94. Guilding C, Piggins HD. Challenging the omnipotence of the suprachiasmatic timekeeper: are circadian oscillators present throughout the mammalian brain? Eur J Neurosci 2007;25:3195-3216.

95. Kalsbeek A, Palm IF, La Fleur SE, Scheer FAJL, Perreau-Lenz S, Ruiter M, et al. SCN outputs and the hypothalamic balance of life. J Biol Rhythms 2006;21:458-469.

96. Ono T, Nishino H, Sasaka K, Muramoto K, Yano I, Simpson A. Para- ventricular nucleus connections to spinal cord and pituitary. Neurosci Lett 1978;10:141-146.

97. la Fleur SE, Kalsbeek A, Wortel J, Buijs RM. Polysynaptic neural pathways between the hypothalamus, including the suprachiasmatic nucleus, and the liver. Brain Res 2000;871:50-56.

98. Shimazu T, Minokoshi Y. Systemic Glucoregulation by Glucose-Sensing Neurons in the Ventromedial Hypothalamic Nucleus (VMH). J Endocr Soc 2017;1:449-459.

99. la Fleur SE, Kalsbeek A, Wortel J, Fekkes ML, Buijs RM. A daily rhythm in glucose tolerance: a role for the suprachiasmatic nucleus. Diabetes 2001;50:1237-1243.

100. Buijs RM, Guzmán Ruiz MA, Méndez Hernández R, Rodríguez Cortés $\mathrm{B}$. The suprachiasmatic nucleus; a responsive clock regulating homeostasis by daily changing the setpoints of physiological parameters. Auton Neurosci 2019;218:43-50.

101. Shiiya T, Nakazato M, Mizuta M, Date Y, Mondal MS, Tanaka M, et al. Plasma ghrelin levels in lean and obese humans and the effect of glucose on ghrelin secretion. J Clin Endocrinol Metab 2002;87:240-244.

102. Kalsbeek A, Fliers E, Romijn JA, la Fleur SE, Wortel J, Bakker O, et al. The suprachiasmatic nucleus generates the diurnal changes in plasma leptin levels. Endocrinology 2001;142:2677-2685.

103. Kalsbeek A, van der Spek R, Lei J, Endert E, Buijs RM, Fliers E. Circadian rhythms in the hypothalamo-pituitary-adrenal (HPA) axis. Mol Cell Endocrinol 2012;349:20-29.

104. Van De Kar LD, Lorens SA. Differential serotonergic innervation of individual hypothalamic nuclei and other forebrain regions by the dorsal and median midbrain raphe nuclei. Brain Res 1979;162:45-54.

105. Malek ZS, Sage D, Pévet P, Raison S. Daily rhythm of tryptophan hydroxylase-2 messenger ribonucleic acid within raphe neurons is induced by corticoid daily surge and modulated by enhanced locomotor activity. Endocrinology 2007;148:5165-5172.

106. Buijs FN, León-Mercado L, Guzmán-Ruiz M, Guerrero-Vargas NN, Romo-Nava F, Buijs RM. The circadian system: a regulatory feedback network of periphery and brain. Physiology 2016;31:170-181.

107. Pontes ALB de, Engelberth RCGJ, Nascimento E da S, Cavalcante JC, Costa MSM de O, Pinato L, et al. Serotonin and circadian rhythms. Psychol Neurosci 2010;3:217-228.

108. Zaki NFW, Spence DW, BaHammam AS, Pandi-Perumal SR, Cardinali DP, Brown GM. Chronobiological theories of mood disorder. Eur Arch Psychiatry Clin Neurosci 2018;268:107-118.

109. Pévet P. Melatonin: from seasonal to circadian signal. J Neuroendocrinol 2003;15:422-426.

110. Reiter RJ. The melatonin rhythm: both a clock and a calendar. Experientia 1993;49:654-664.

111. Cagnacci A, Elliott JA, Yen SS. Melatonin: a major regulator of the circadian rhythm of core temperature in humans. J Clin Endocrinol Metab 1992;75:447-452.

112. Chenu F, El Mansari M, Blier P. Electrophysiological effects of repeated administration of agomelatine on the dopamine, norepinephrine, and serotonin systems in the rat brain. Neuropsychopharmacology 2013;38:275-284

113. Kalsbeek A, Cutrera R, van Heerikhuize J, van der Vliet J, Buijs R. GABA release from suprachiasmatic nucleus terminals is necessary for the light-induced inhibition of nocturnal melatonin release in the rat. Neuroscience 1999;91:453-461.

114. Khaldy H, León J, Escames G, Bikjdaouene L, García JJ, Acuña-Castroviejo D. Circadian rhythms of dopamine and dihydroxyphenyl acetic acid in the mouse striatum: effects of pinealectomy and of melatonin treatment. Neuroendocrinology 2002;75:201-208.

115. Uz T, Akhisaroglu M, Ahmed R, Manev H. The pineal gland is critical for circadian period 1 expression in the striatum and for circadian cocaine sensitization in mice. Neuropsychopharmacology 2003;28: 2117-2123.

116. Macchi MM, Bruce JN. Human pineal physiology and functional significance of melatonin. Front Neuroendocrinol 2004;25:177-195. 
117. Burton R. The Natomy of Melancholy. London: Oxford University Press; 1621.

118. Richter CP. Biological Clocks in Medicine and Psychiatry. Springfield, Illinois: Charles C. Thomas.; 1965.

119. Souêtre E, Salvati E, Belugou J-L, Pringuey D, Candito M, Krebs B, et al. Circadian rhythms in depression and recovery: evidence for blunted amplitude as the main chronobiological abnormality. Psychiatry Res 1989;28:263-278.

120. Atkinson M, Kripke DF, Wolf SR. Autorhythmometry in manic-depressives. Chronobiologia 1975;2:325-335.

121. Hall P, Spear FG, Stirland D. Diurnal variation of subjective mood in depressive states. Psychiatr Q 1964;38:529-536.

122. Wehr TA, Wirz-Justice A. Circadian rhythm mechanisms in affective illness and in antidepressant drug action. Pharmacopsychiatria 1982; 15:31-39.

123. Zung WWK, Green RL. Seasonal variation of suicide and depression. Arch Gen Psychiatry 1974;30:89-91.

124. Milstein V, Small JG, Shelbourne D, Small IF. Manic depressive illness: onset, diurnal temperature and season of birth. Dis Nerv Syst 1976; 37:373-375.

125. Eastwood MR, Peacocke J. Seasonal patterns of suicide, depression and electroconvulsive therapy. Br J Psychiatry 1976;129:472-475.

126. Frangos E, Athanassenas G, Tsitourides S, Psilolignos P, Robos A, Katsanou N, et al. Seasonality of the episodes of recurrent affective psychoses: possible prophylactic interventions. J Affect Disord 1980; 2:239-247.

127. Berkol TD, Seren Kirlioğlu S, Balcioğlu YH, Üstün N, İslam S, Özyildirim İ. Comparison of sociodemographic and clinical characteristics of bipolar patients with and without seasonal patterns. Anadolu Psikiyatr Derg 2017;18.

128. Faedda GL, Tondo L, Teicher MH, Baldessarini RJ, Gelbard HA, Floris GF. Seasonal mood disorders: patterns of seasonal recurrence in mania and depression. Arch Gen Psychiatry 1993;50:17-23.

129. Iasevoli F, Avvisati L, Gilardi V, Latte G, Prinzivalli E, de Berardis D, et al. Chronobiology of Mood Disorders. In: López-Muñoz F, Srinivasan V, de Berardis D, Álamo C, Kato T, Editors. Melatonin, Neuroprotective Agents and Antidepressant Therapy. New Delhi: Springer, 2016, p.273-295.

130. McClung CA. How might circadian rhythms control mood? Let me count the ways... Biol Psychiatry 2013;74:242-249.

131. Wehr TA, Sack D, Rosenthal N, Duncan W, Gillin JC. Circadian rhythm disturbances in manic-depressive illness. Fed Proc 1983;42:28092814.

132. Wirz-Justice A, Pühringer W, Hole G. Sleep deprivation and clomipramine in endogenous depression. Lancet 1976;308:912.

133. Wirz-Justice A, Tobler I, Kafka MS, Naber D, Marangos PJ, Borbély AA, et al. Sleep deprivation: effects on circadian rhythms of rat brain neurotransmitter receptors. Psychiatry Res 1981;5:67-76.

134. Simon RD. Shift work disorder: clinical assessment and treatment strategies. J Clin Psychiatry 2012;73:e20.

135. Vargas I, Garland SN, Kloss JD, Perlis ML. Insomnia and psychiatric disorders. Sleep Heal 2019:373-389.

136. Vadnie CA, McClung CA. Circadian rhythm disturbances in mood disorders: insights into the role of the suprachiasmatic nucleus. Neural Plast 2017;2017:1-28.

137. Stubbs B, Wu Y-T, Prina AM, Leng Y, Cosco TD. A population study of the association between sleep disturbance and suicidal behaviour in people with mental illness. J Psychiatr Res 2016;82:149-154.

138. Monteleone P, Maj M. The circadian basis of mood disorders: Recent developments and treatment implications. Eur Neuropsychopharmacol 2008;18:701-711.

139. Kupfer DJ, Foster FG, Coble P, McPartland RJ, Ulrich RF. The application of EEG sleep for the differential diagnosis of affective disorders. Am J Psychiatry 1978;135:69-74.

140. Kupfer DJ, Foster FG. Interval between onset of sleep and rapid-eye- movement sleep as an indicator of depression. Lancet 1972;300:684686.

141. Kupfer DJ, Ulrich RF, Coble PA, Jarrett DB, Grochocinski V, Doman J, et al. Application of automated REM and slow wave sleep analysis: II. Testing the assumptions of the two-process model of sleep regulation in normal and depressed subjects. Psychiatry Res 1984;13:335-343.

142. Rush AJ, Erman MK, Giles DE, Schlesser MA, Carpenter G, Vasavada $\mathrm{N}$, et al. Polysomnographic findings in recently drug-free and clinically remitted depressed patients. Arch Gen Psychiatry 1986;43:878884 .

143. Giles DE, Jarrett RB, Roffwarg HP, Rush AJ. Reduced rapid eye movement latency. A predictor of recurrence in depression. Neuropsychopharmacology 1987;1:33-39.

144. Pillai V, Kalmbach DA, Ciesla JA. A meta-analysis of electroencephalographic sleep in depression: evidence for genetic biomarkers. Biol Psychiatry 2011;70:912-919.

145. Rotenberg VS, Shamir E, Barak Y, Indursky P, Kayumov L, Mark M. REM sleep latency and wakefulness in the first sleep cycle as markers of major depression: a controlled study vs. schizophrenia and normal controls. Prog Neuro-Psychopharmacology Biol Psychiatry 2002;26: 1211-1215.

146. Steiger A, Kimura M. Wake and sleep EEG provide biomarkers in depression. J Psychiatr Res 2010;44:242-252.

147. Monteleone P, Martiadis V, Maj M. Circadian rhythms and treatment implications in depression. Prog Neuro-Psychopharmacology Biol Psychiatry 2011;35:1569-1574.

148. De Berardis D, Orsolini L, Serroni N, Girinelli G, Iasevoli F, Tomasetti $\mathrm{C}$, et al. The role of melatonin in mood disorders. ChronoPhysiology Ther 2015;5:65-75.

149. Emens J, Lewy A, Kinzie JM, Arntz D, Rough J. Circadian misalignment in major depressive disorder. Psychiatry Res 2009;168:259-261.

150. Shafii M, MacMillan DR, Key MP, Derrick AM, Kaufman N, Nahinsky ID. Nocturnal serum melatonin profile in major depression in children and adolescents. Arch Gen Psychiatry 1996;53:1009-1013.

151. Hasler BP, Buysse DJ, Kupfer DJ, Germain A. Phase relationships between core body temperature, melatonin, and sleep are associated with depression severity: further evidence for circadian misalignment in non-seasonal depression. Psychiatry Res 2010;178:205-207.

152. Cagnacci A, Kräuchi K, Wirz-Justice A, Volpe A. Homeostatic versus circadian effects of melatonin on core body temperature in humans. J Biol Rhythms 1997;12:509-517.

153. Wirz-Justice A. Biological rhythm disturbances in mood disorders. Int Clin Psychopharmacol 2006;21:S11-S15.

154. Kennaway DJ. Clock genes at the heart of depression. J Psychopharmacol 2010;24:5-14.

155. Etain B, Milhiet V, Bellivier F, Leboyer M. Genetics of circadian rhythms and mood spectrum disorders. Eur Neuropsychopharmacol 2011;21: S676-S682.

156. Melhuish Beaupre L, Brown GM, Kennedy JL. Circadian genes in major depressive disorder. World J Biol Psychiatry 2020;21:80-90.

157. Herbert J, Goodyer IM, Grossman AB, Hastings MH, de Kloet ER, Lightman SL, et al. Do corticosteroids damage the brain? J Neuroendocrinol 2006;18:393-411.

158. Dumbell R, Matveeva O, Oster H. Circadian clocks, stress, and immunity. Front Endocrinol (Lausanne) 2016;7:37.

159. Carroll BJ, Martin FI, Davies B. Resistance to suppression by dexamethasone of plasma 11-O.H.C.S. levels in severe depressive illness. Br Med J 1968;3:285-287.

160. Keller J, Gomez R, Williams G, Lembke A, Lazzeroni L, Murphy GM, et al. HPA axis in major depression: cortisol, clinical symptomatology and genetic variation predict cognition. Mol Psychiatry 2017;22:527536.

161. Gold PW. The organization of the stress system and its dysregulation in depressive illness. Mol Psychiatry 2015;20:32-47.

162. Goodyer IM, Herbert J, Altham PME. Adrenal steroid secretion and 
major depression in 8- to 16-year-olds, III. Influence of cortisol/DHEA ratio at presentation on subsequent rates of disappointing life events and persistent major depression. Psychol Med 1998;28:265-273.

163. Gallagher P, Young A. Cortisol/DHEA ratios in depression [2]. Neuropsychopharmacology 2002;26:410.

164. Markopoulou K, Papadopoulos A, Juruena MF, Poon L, Pariante CM, Cleare AJ. The ratio of cortisol/DHEA in treatment resistant depression. Psychoneuroendocrinology 2009;34:19-26.

165. Pariante CM, Lightman SL. The HPA axis in major depression: classical theories and new developments. Trends Neurosci 2008;31:464468.

166. Carvalho LA, Garner BA, Dew T, Fazakerley H, Pariante CM. Antidepressants, but not antipsychotics, modulate GR function in human whole blood: an insight into molecular mechanisms. Eur Neuropsychopharmacol 2010;20:379-387.

167. Raison CL, Miller AH. Is depression an inflammatory disorder? Curr Psychiatry Rep 2011;13:467-475.

168. Pasco JA, Nicholson GC, Williams LJ, Jacka FN, Henry MJ, Kotowicz MA, et al. Association of high-sensitivity C-reactive protein with de novo major depression. Br J Psychiatry 2010;197:372-377.

169. Postal M, Appenzeller S. The importance of cytokines and autoantibodies in depression. Autoimmun Rev 2015;14:30-35.

170. Felger JC, Lotrich FE. Inflammatory cytokines in depression: Neurobiological mechanisms and therapeutic implications. Neuroscience 2013;246:199-229.

171. Narasimamurthy R, Hatori M, Nayak SK, Liu F, Panda S, Verma IM. Circadian clock protein cryptochrome regulates the expression of proinflammatory cytokines. Proc Natl Acad Sci 2012;109:12662-12667.

172. Imeri L, Opp MR. How (and why) the immune system makes us sleep. Nat Rev Neurosci 2009;10:199-210.

173. Irwin MR, Olmstead R, Carroll JE. Sleep disturbance, Sleep duration, and inflammation: a systematic review and meta-analysis of cohort studies and experimental sleep deprivation. Biol Psychiatry 2016;80: 40-52.

174. Plante DT, Winkelman JW. Sleep disturbance in bipolar disorder: therapeutic implications. Am J Psychiatry 2008;165:830-843.

175. Harvey AG. Sleep and circadian rhythms in bipolar disorder: seeking synchrony, harmony, and regulation. Am J Psychiatry 2008;165:820829.

176. Dallaspezia S, Benedetti F. Sleep in Other Psychiatric Disorders. In: Chokroverty S, Ferini-Strambi L, Editors. Oxford Textbook of Sleep Disorders. Oxford: Oxford University Press, 2017, p.451.

177. Rocha PMB, Neves FS, Corrêa H. Significant sleep disturbances in euthymic bipolar patients. Compr Psychiatry 2013;54:1003-1008.

178. Geoffroy PA, Scott J, Boudebesse C, Lajnef M, Henry C, Leboyer M, et al. Sleep in patients with remitted bipolar disorders: a meta-analysis of actigraphy studies. Acta Psychiatr Scand 2015;131:89-99.

179. Kaplan KA, McGlinchey EL, Soehner A, Gershon A, Talbot LS, Eidelman $\mathrm{P}$, et al. Hypersomnia subtypes, sleep and relapse in bipolar disorder. Psychol Med 2015;45:1751-1763.

180. Boudebesse C, Geoffroy PA, Bellivier F, Henry C, Folkard S, Leboyer $\mathrm{M}$, et al. Correlations between objective and subjective sleep and circadian markers in remitted patients with bipolar disorder. Chronobiol Int 2014;31:698-704.

181. Sylvia LG, Chang WC, Kamali M, Tohen M, Kinrys G, Deckersbach $\mathrm{T}$, et al. Sleep disturbance may impact treatment outcome in bipolar disorder: a preliminary investigation in the context of a large comparative effectiveness trial. J Affect Disord 2018;225:563-568.

182. Harvey AG, Soehner AM, Kaplan KA, Hein K, Lee J, Kanady J, et al. Treating insomnia improves mood state, sleep, and functioning in bipolar disorder: a pilot randomized controlled trial. J Consult Clin Psychol 2015;83:564-577.

183. Kanady JC, Soehnera AM, Harvey AG. A Retrospective examination of sleep disturbance across the course of bipolar disorder. J Sleep Disord Ther 2015;4:1000193.
184. Ng TH, Chung KF, Ho FY, Yeung WF, Yung KP, Lam TH. Sleepwake disturbance in interepisode bipolar disorder and high-risk individuals: a systematic review and meta-analysis. Sleep Med Rev 2015; 20:46-58.

185. Robillard R, Naismith SL, Rogers NL, Scott EM, Ip TKC, Hermens DF, et al. Sleep-Wake cycle and melatonin rhythms in adolescents and young adults with mood disorders: comparison of unipolar and bipolar phenotypes. Eur Psychiatry 2013;28:412-416.

186. Nováková M, Praško J, Látalová K, Sládek M, Sumová A. The circadian system of patients with bipolar disorder differs in episodes of mania and depression. Bipolar Disord 2015;17:303-314.

187. Kennedy SH, Tighe S, McVey G, Brown GM. Melatonin and cortisol "switches" during mania, depression, and euthymia in a drug-free bipolar patient. J Nerv Ment Dis 1989;177:300-303.

188. Lewy AJ, Wehr TA, Gold PW, Goodwin FK. Plasma melatonin in manic-depressive illness. Catech Basic Clin Front 1979:1173-1175.

189. Lewy AJ, Wehr TA, Goodwin FK, Newsome DA, Rosenthal NE. Manic-depressive patients may be supersensitive to light. Lancet 1981; 317:383-384.

190. Livianos L, Sierra P, Arques S, García A, Rojo L. Is melatonin an adjunctive stabilizer? Psychiatry Clin Neurosci 2012;66:82-83.

191. Geoffroy PA. Clock genes and light signaling alterations in bipolar disorder: when the biological clock is off. Biol Psychiatry 2018;84: 775-777.

192. McCarthy MJ, Welsh DK. Cellular circadian clocks in mood disorders. J Biol Rhythms 2012;27:339-352.

193. Coque L, Mukherjee S, Cao JL, Spencer S, Marvin M, Falcon E, et al. Specific role of VTA dopamine neuronal firing rates and morphology in the reversal of anxiety-Rrelated, but not depression-related behavior in the clock $\Delta 19$ mouse model of mania. Neuropsychopharmacology 2011;36:1478-1488.

194. Abarca C, Albrecht U, Spanagel R, Takahashi JS, White FJ, Cooper DC, et al. Cocaine sensitization and reward are under the influence of circadian genes and rhythm. Proc Natl Acad Sci U S A 2002;99: 9026-9030.

195. Roybal K, Theobold D, Graham A, DiNieri JA, Russo SJ, Krishnan V, et al. Mania-like behavior induced by disruption of CLOCK. Proc Natl Acad Sci U S A 2007;104:6406-6411.

196. Parekh PK, Becker-Krail D, Sundaravelu P, Ishigaki S, Okado H, Sobue G, et al. Altered GluA1 (Grial) function and accumbal synaptic plasticity in the Clock $\Delta 19$ model of bipolar mania. Biol Psychiatry 2018;84:817-826.

197. Gekakis N, Staknis D, Nguyen HB, Davis FC, Wilsbacher LD, King DP, et al. Role of the CLOCK protein in the mammalian circadian mechanism. Science 1998;280:1564-1569.

198. Pawlak J, Dmitrzak-Weglarz M, Maciukiewicz M, Wilkosc M, Leszczynska-Rodziewicz A, Zaremba D, et al. Suicidal behavior in the context of disrupted rhythmicity in bipolar disorder- Data from an association study of suicide attempts with clock genes. Psychiatry Res. 2015;226:517-520.

199. Belvederi Murri M, Prestia D, Mondelli V, Pariante C, Patti S, Olivieri $\mathrm{B}$, et al. The HPA axis in bipolar disorder: systematic review and metaanalysis. Psychoneuroendocrinology 2016;63:327-342.

200. Sigitova E, Fišar Z, Hroudová J, Cikánková T, Raboch J. Biological hypotheses and biomarkers of bipolar disorder. Psychiatry Clin Neurosci 2017;71:77-103.

201. Girshkin L, Matheson SL, Shepherd AM, Green MJ. Morning cortisol levels in schizophrenia and bipolar disorder: a meta-analysis. Psychoneuroendocrinology 2014;49:187-206.

202. Modabbernia A, Taslimi S, Brietzke E, Ashrafi M. Cytokine alterations in bipolar disorder: a meta-analysis of 30 studies. Biol Psychiatry 2013;74:15-25.

203. Brietzke E, Stertz L, Fernandes BS, Kauer-Sant'Anna M, Mascarenhas M, Escosteguy Vargas A, et al. Comparison of cytokine levels in depressed, manic and euthymic patients with bipolar disorder. J Affect 
Disord 2009;116:214-217.

204. Bai YM, Su TP, Li CT, Tsai SJ, Chen MH, Tu PC, et al. Comparison of pro-inflammatory cytokines among patients with bipolar disorder and unipolar depression and normal controls. Bipolar Disord 2015;17:269277.

205. Peirson SN, Foster RG. Sleep and Circadian Rhythm Disruption in Psychosis. In: Colwell CS, Editor. Circadian Medicine. New York: Wiley-Blackwell, 2015, p.271-282.

206. Wulff K, Dijk DJ, Middleton B, Foster RG, Joyce EM. Sleep and circadian rhythm disruption in schizophrenia. Br J Psychiatry 2012;200: 308-316.

207. Howes OD, Kapur S. The dopamine hypothesis of schizophrenia: version III--the final common Pathway. Schizophr Bull 2009;35:549-562.

208. Yates NJ. Schizophrenia: the role of sleep and circadian rhythms in regulating dopamine and psychosis. Rev Neurosci 2016;27:669-687.

209. Monti JM, BaHammam AS, Pandi-Perumal SR, Bromundt V, Spence DW, Cardinali DP, et al. Sleep and circadian rhythm dysregulation in schizophrenia. Prog Neuro-Psychopharmacology Biol Psychiatry 2013;43:209-216.

210. Fasshauer D, Sutton RB, Brunger AT, Jahn R, Vikman J, Molnár Z, et al. Conserved structural features of the synaptic fusion complex: SNARE proteins reclassified as Q- and R-SNAREs. Proc Natl Acad Sci 1998; 95:15781-15786.

211. Oliver PL, Davies KE. Interaction between environmental and genetic factors modulates schizophrenic endophenotypes in the Snap- 25 mouse mutant blind-drunk. Hum Mol Genet 2009;18:4576-4589.

212. Oliver PL, Sobczyk MV, Maywood ES, Edwards B, Lee S, Livieratos A, et al. Disrupted circadian rhythms in a mouse model of schizophrenia. Curr Biol 2012;22:314-319.

213. Lamont EW, Coutu DL, Cermakian N, Boivin DB. Circadian rhythms and clock genes in psychotic disorders. Isr J Psychiatry Relat Sci 2010;47:27-35.

214. Cosgrave J, Wulff K, Gehrman P. Sleep, circadian rhythms, and schizophrenia. Curr Opin Psychiatry 2018;31:176-182.

215. Sasidharan A, Kumar S, Nair AK, Lukose A, Marigowda V, John JP, et al. Further evidences for sleep instability and impaired spindle-delta dynamics in schizophrenia: a whole-night polysomnography study with neuroloop-gain and sleep-cycle analysis. Sleep Med 2017;38:1-13.

216. Chan MS, Chung KF, Yung KP, Yeung WF. Sleep in schizophrenia: a systematic review and meta-analysis of polysomnographic findings in case-control studies. Sleep Med Rev 2017;32:69-84.

217. Kaskie RE, Gill KM, Ferrarelli F. Reduced frontal slow wave density during sleep in first-episode psychosis. Schizophr Res 2019;206:318324.

218. Bian Y, Liang W, Yue W, Han X, Lin C, Zhang J, et al. Meta-analysis of sleep structure in patients with untreated schizophrenia. Chinese Ment Heal J 2017;31:208-214.

219. Li SX, Lam SP, Zhang J, Yu MWM, Chan JWY, Chan CSY, et al. Sleep disturbances and suicide risk in an 8-year longitudinal study of schizophrenia-spectrum disorders. Sleep 2016;39:1275-1282.

220. Anderson G, Maes M. Melatonin: an overlooked factor in schizophrenia and in the inhibition of anti-psychotic side effects. Metab Brain Dis 2012;27:113-119.

221. Olcese JM, Cao C, Mori T, Mamcarz MB, Maxwell A, Runfeldt MJ, et al. Protection against cognitive deficits and markers of neurodegeneration by long-term oral administration of melatonin in a transgenic model of Alzheimer disease. J Pineal Res 2009;47:82-96.

222. Galván-Arrieta T, Trueta C, Cercós MG, Valdés-Tovar M, Alarcón S, Oikawa J, et al. The role of melatonin in the neurodevelopmental etiology of schizophrenia: A study in human olfactory neuronal precursors. J Pineal Res 2017;63:e12421.

223. Rao ML, Gross G, Strebel B, Halaris A, Huber G, Bräunig P, et al. Circadian rhythm of tryptophan, serotonin, melatonin, and pituitary hormones in schizophrenia. Biol Psychiatry 1994;35:151-163.

224. Sandyk R, Kay SR. The relationship of pineal calcification to cortical atrophy in schizophrenia. Int J Neurosci 1991;57:179-191.

225. Witkovsky P. Dopamine and retinal function. Doc Ophthalmol 2004; 108:17-39.

226. Tardito D, Milanese M, Bonifacino T, Musazzi L, Grilli M, Mallei A, et al. Blockade of stress-induced increase of glutamate release in the rat prefrontal/frontal cortex by agomelatine involves synergy between melatonergic and 5-HT2Creceptor-dependent pathways. BMC Neurosci 2010;11:1-4.

227. Lewis DA, Moghaddam B. Cognitive dysfunction in schizophrenia: convergence of $\gamma$-aminobutyric acid and glutamate alterations. Arch Neurol 2006;63:1372-1376.

228. Gorfine T, Assaf Y, Goshen-Gottstein Y, Yeshurun Y, Zisapel N. Sleepanticipating effects of melatonin in the human brain. Neuroimage 2006;31:410-418

229. Shamir E, Barak Y, Shalman I, Laudon M, Zisapel N, Tarrasch R, et al. Melatonin Treatment for Tardive Dyskinesia. Arch Gen Psychiatry 2001;58:1049-1052.

230. Onaolapo AY, Aina OA, Onaolapo OJ. Melatonin attenuates behavioural deficits and reduces brain oxidative stress in a rodent model of schizophrenia. Biomed Pharmacother 2017;92:373-383.

231. Zubin J, Spring B. Vulnerability: a new view of schizophrenia. J Abnorm Psychol 1977;86:103-126.

232. Coulon N, Brailly-Tabard S, Walter M, Tordjman S. Altered circadian patterns of salivary cortisol in individuals with schizophrenia: a critical literature review. J Physiol 2016;110:439-447.

233. Singh M, Solanki RK, Bagaria B, Swami MK. Hypothalamic-PituitaryAdrenal (HPA) axis functioning among patients with schizophrenia: a cross sectional comparative study. J Psychiatry (South Africa) 2015;18: 1000211.

234. Mittal VA, Walker EF. Minor physical anomalies and vulnerability in prodromal youth. Schizophr Res 2011;129:116-121.

235. Carol EE, Mittal VA. Resting cortisol level, self-concept, and putative familial environment in adolescents at ultra high-risk for psychotic disorders. Psychoneuroendocrinology 2015;57:26-36.

236. Bradley AJ, Dinan TG. Review: a systematic review of hypothalamicpituitary-adrenal axis function in schizophrenia: implications for mortality. J Psychopharmacol 2010;24:91-118.

237. Zorn J V, Schür RR, Boks MP, Kahn RS, Joëls M, Vinkers CH. Cortisol stress reactivity across psychiatric disorders: a systematic review and meta-analysis. Psychoneuroendocrinology 2017;77:25-36.

238. Remes O, Brayne C, van der Linde R, Lafortune L. A systematic review of reviews on the prevalence of anxiety disorders in adult populations. Brain Behav 2016;6:e00497.

239. Boland EM, Ross RJ. Recent advances in the study of sleep in the anxiety disorders, obsessive-compulsive disorder, and posttraumatic stress disorder. Psychiatr Clin North Am 2015;38:761-776.

240. Cox RC, Olatunji BO. A systematic review of sleep disturbance in anxiety and related disorders. J Anxiety Disord 2016;37:104-129.

241. Mesa F, Beidel DC, Bunnell BE. An examination of psychopathology and daily impairment in adolescents with social anxiety disorder. PLoS One 2014;9:e93668.

242. Brown TM, Black B, Uhde TW. The sleep architecture of social phobia. Biol Psychiatry 1994;35:420-421.

243. American Psychiatric Association. Diagnostic and Statistical Manual of Mental Disorders: DSM-5. 5th Ed. Washington, D.C.: American Psychiatric Pub; 2013.

244. Cox RC, Olatunji BO. Circadian rhythms in obsessive-compulsive disorder: recent findings and recommendations for future research. Curr Psychiatry Rep 2019;21:54.

245. Kupfer D, Foster FG. Interval between onset of sleep and rapid-eyemovement sleep as an indicator of depression. Lancet 1972;300:684686.

246. Kupfer DJ. REM latency: a psychobiologic marker for primary depressive disease. Biol Psychiatry 1976;11:159-174.

247. Sitaram N, Nurnberger JI, Gershon ES, Gillin JC. Cholinergic regula- 
tion of mood and REM sleep: Potential model and marker of vulnerability to affective disorder. Am J Psychiatry 1982;139:571-576.

248. Millar A, Espie CA, Scott J. The sleep of remitted bipolar outpatients: a controlled naturalistic study using actigraphy. J Affect Disord 2004; 80:145-153.

249. Hudson JI, Lipinski JF, Keck PE, Aizley HG, Lukas SE, Rothschild AJ, et al. Polysomnographic characteristics of young manic patients: comparison with unipolar depressed patients and normal control subjects. Arch Gen Psychiatry 1992;49:378-383.

250. Linkowski P, Mendlewicz J. Sleep electroencephalogram and rhythm disturbances in mood disorders. Curr Opin Psychiatry 1993;6:35-37.

251. Hudson JI, Lipinski JF, Frankenburg FR, Grochocinski VJ, Kupfer DJ. Electroencephalographic sleep in mania. Arch Gen Psychiatry 1988; 45:267-273.

252. Gillin JC, Duncan W, Pettigrew KD, Frankel BL, Snyder F. Successful separation of depressed, normal, and insomniac subjects by EEG sleep data. Arch Gen Psychiatry 1979;36:85-90.

253. Lauer CJ, Wiegand M, Krieg JC. All-night electroencephalographic sleep and cranial computed tomography in depression - A study of unipolar and bipolar patients. Eur Arch Psychiatry Clin Neurosci 1992;242:59-68.

254. Giles DE, Rush AJ, Roffwarg HP. Sleep parameters in bipolar I, bipolar II, and unipolar depressions. Biol Psychiatry 1986;21:1340-1343.

255. Fossion P, Staner L, Dramaix M, Kempenaers C, Kerkhofs M, Hubain $\mathrm{P}$, et al. Does sleep EEG data distinguish between UP, BPI or BPII major depressions? An age and gender controlled study. J Affect Disord 1998:49:181-187.

256. Jernajczyk W. Latency of eye movement and other REM sleep parameters in bipolar depression. Biol Psychiatry 1986;21:465-472.

257. Bian Y, Liang WY, Yue WH, Han XL, Lin C, Zhang J, et al. Sleep architecture in drug naive patients with schizophrenia: a meta-analysis. Chinese Ment Heal J 2017;31:208-214.

258. Nelson JC, Davis JM. DST studies in psychotic depression: a metaanalysis. Am J Psychiatry 1997;154:1497-1503.

259. Keller J, Flores B, Gomez RG, Solvason HB, Kenna H, Williams GH, et al. Cortisol circadian rhythm alterations in psychotic major depression. Biol Psychiatry 2006;60:275-281.

260. Belanoff JK, Kalehzan M, Sund B, Fleming Ficek SK, Schatzberg AF. Cortisol activity and cognitive changes in psychotic major depression. Am J Psychiatry 2001;158:1612-1616.

261. Gold PW. The organization of the stress system and its dysregulation in depressive illness. Mol Psychiatry 2014;20:32-47.

262. Pelham RW, Vaughan GM, Sandock KL, Vaughan, MK. Twenty-fourhour cycle of a melatonin-like substance in the plasma of human males. J Clin Endocrinol Metab 1973;37:341-344.

263. Wetterberg L. Clinical importance of melatonin. Prog Brain Res 1979; 52:539-547.

264. Claustrat B, Chazot G, Brun J, Jordan D, Sassolas G. A chronobiological study of melatonin and cortisol secretion in depressed subjects: plasma melatonin, a biochemical marker in major depression. Biol Psychiatry 1984;19:1215-1228.

265. Parry BL, Newton RP. Chronobiological basis of female-specific mood disorders. Neuropsychopharmacology 2001;25:S102-S108.

266. Beck-Friis J, Kjellman BF, Aperia B, Unden F, von Rosen D, Ljunggren JG, et al. Serum melatonin in relation to clinical variables in patients with major depressive disorder and a hypothesis of a low melatonin syndrome. Acta Psychiatr Scand 1985;71:319-330.
267. Nair NPV, Hariharasubramanian N, Pilapil C. Circadian rhythm of plasma melatonin in endogenous depression. Prog Neuropsychopharmacol Biol Psychiatry 1984;8:715-718.

268. Brown R, Kocsis JH, Caroff S, Amsterdam J, Winokur A, Stokes PE, et al. Differences in nocturnal melatonin secretion between melancholic depressed patients and control subjects. Am J Psychiatry 1985;142: 811-816.

269. Frazer A, Brown R, Kocsis J, Caroff S, Amsterdam J, Winokur A, et al. Patterns of melatonin rhythms in depression. J Neural Transm Suppl 1986;21:269-290.

270. Fountoulakis KN, Karamouzis M, Iacovides A, Nimatoudis J, Diakogiannis J, Kaprinis G, et al. Morning and evening plasma melatonin and dexamethasone suppression test in patients with nonseasonal major depressive disorder from northern Greece (latitude 40-41.5 ). Neuropsychobiology 2001;44:113-117.

271. Paparrigopoulos T. Melatonin response to atenolol administration in depression: indication of $\beta$-adrenoceptor dysfunction in a subtype of depression. Acta Psychiatr Scand 2002;106:440-445.

272. Wehr TA, Sack DA, Duncan WC, Mendelson WB, Rosenthal NE, Gillin JC, et al. Sleep and circadian rhythms in affective patients isolated from external time cues. Psychiatry Res 1985;15:327-339.

273. Buckley TM, Schatzberg AF. A pilot study of the phase angle between cortisol and melatonin in major depression - A potential biomarker? J Psychiatr Res 2010;44:69-74.

274. Khaleghipour S, Masjedi M, Ahade H, Enayate M, Pasha G, Nadery F, et al. Morning and nocturnal serum melatonin rhythm levels in patients with major depressive disorder: an analytical cross-sectional study. Sao Paulo Med J 2012;130:167-172.

275. Crasson M, Kjiri S, Colin A, Kjiri K, L'Hermite-Baleriaux M, Ansseau $\mathrm{M}$, et al. Serum melatonin and urinary 6-sulfatoxymelatonin in major depression. Psychoneuroendocrinology 2004;29:1-12.

276. Tuunainen A, Kripke DF, Elliott JA, Assmus JD, Rex KM, Klauber $\mathrm{MR}$, et al. Depression and endogenous melatonin in postmenopausal women. J Affect Disord 2002;69:149-158.

277. Rahman SA, Marcu S, Kayumov L, Shapiro CM. Altered sleep architecture and higher incidence of subsyndromal depression in low endogenous melatonin secretors. Eur Arch Psychiatry Clin Neurosci 2010;260:327-335.

278. Beck-Friis J, von Rosen D, Kjellman BF, Ljunggren JG, Wetterberg L. Melatonin in relation to body measures, sex, age, season and the use of drugs in patients with major affective disorders and healthy subjects. Psychoneuroendocrinology 1984;9:261-277.

279. Kennedy SH, Kutcher SP, Ralevski E, Brown GM. Nocturnal melatonin and 24-hour 6-sulphatoxymelatonin levels in various phases of bipolar affective disorder. Psychiatry Res 1996;63:219-222.

280. Monteleone P, Natale M, La Rocca A, Maj M. Decreased nocturnal secretion of melatonin in drug-free schizophrenics: No change after subchronic treatment with antipsychotics. Neuropsychobiology 1997; 36:159-163.

281. Monteleone P, Maj M, Fusco M, Kemali D, Reiter RJ. Depressed nocturnal plasma melatonin levels in drug-free paranoid schizophrenics. Schizophr Res 1992;7:77-84.

282. Bersani G, Mameli M, Garavini A, Pancheri P, Nordio M. Reduction of night/day difference in melatonin blood levels as a possible diseaserelated index in schizophrenia. Neuroendocrinol Lett 2003;24:181184. 